\title{
Explaining repo specialness
}

\section{Alfonso Dufour ${ }^{1}$ ｜ Miriam Marra ${ }^{1}$ ～Ivan Sangiorgi ${ }^{1}$ (i) ｜ Frank S. Skinner}

${ }^{1}$ ICMA Centre, Henley Business School, University of Reading, Whiteknights

Campus, Reading, UK

${ }^{2}$ Kingston Lane, Brunel University London, Uxbridge, Middlesex, UK

\section{Correspondence}

Ivan Sangiorgi, Lecturer in Finance at the ICMA Centre, Henley Business School, University of Reading, Whiteknights Campus, Reading RG6 6BA, UK.

Email: ivan.sangiorgi@icmacentre.ac.uk

\begin{abstract}
We study the dynamics of specialness for 1-day repo contracts on Italian government bonds over a 10-year sample period. As predicted by Duffie's (1996) model, our results show that collateral supply is a significant factor for specialness. However, we enrich that finding by also showing a clear impact from repo liquidity, collateral riskiness, information uncertainty, and short-selling proxies, revealing the importance of speculative bond demand for specialness. During crisis periods, bond fire sales and European Central Bank interventions also have a large impact on repo specialness. We identify recurrent patterns for specialness around bond auctions. Specialness increases steadily from the auction announcement date until a few days before the auction settlement date, which is consistent with overbidding behaviour and a short selling of treasuries (via reverse repos) from primary dealers ahead of auctions.
\end{abstract}

\section{K E Y W O R D S}

auctions, fire sales, high-frequency data, liquidity, repo specialness, short selling

J E L C L A S S I F I C A T I O N

E43; E51; G01; G12; G15; G24

\section{1 | INTRODUCTION}

The aim of this paper is to explain the variation in the degree of specialness of repurchase agreements (repos) that use Italian government coupon bonds (BTPs-Buoni del Tesoro Pluriennali) as collateral. Repos are financial instruments for collateralized borrowing and they are essential for wellfunctioning and efficient bond markets. Repos are used by bond market participants to either finance long bond positions or initiate short bond positions. Repo markets are also a preferred monetary transmission channel used by central banks to conduct money market operations and regulate financial market liquidity. ${ }^{1}$ Repo markets are characterized by huge transaction volumes, as reported in Table 1, which presents data for the Mercato dei Titoli di Stato (MTS). The MTS is one of the largest European electronic bond and repo markets and the largest one for Italian government bonds (Dunne, Moore, \& Portes, 2006). During our sample period from April 1, 2003 to December 6, 2013, the overall value and the daily average value of all repo transactions executed on the MTS are about $€ 179$ trillion and $€ 65$ billion, respectively.

In a general collateral (GC) repo, the borrower can specify the securities they want to use as collateral after the repo trade is agreed. The collateral is chosen from a predefined basket of treasuries. In contrast, in a special collateral repo, the borrower specifies a unique security as collateral at the outset of a repo transaction and pays a (generally) lower "special" repo interest rate on the loan. At each point time, the difference between the general and the special collateral repo rates measures the "degree of specialness" of the bond used as collateral in the special collateral repo. Positive 
TA B L E 1 Nominal amount of transacted collateral in the MTS repo market

\begin{tabular}{|c|c|c|c|}
\hline & $\begin{array}{l}\text { General } \\
\text { Collateral } \\
\text { (Euro } \\
\text { Billions) }\end{array}$ & $\begin{array}{l}\text { Special } \\
\text { Collateral } \\
\text { (Euro } \\
\text { Billions) }\end{array}$ & $\begin{array}{l}\text { Total (Euro } \\
\text { Billions) }\end{array}$ \\
\hline $\begin{array}{l}\text { Daily } \\
\text { average }\end{array}$ & 28.90 & 36.57 & 65.45 \\
\hline $\begin{array}{l}\text { Standard } \\
\text { deviation }\end{array}$ & 9.54 & 11.27 & 13.98 \\
\hline Minimum & 0.75 & 0.06 & 0.06 \\
\hline Maximum & 99.28 & 130.66 & 189.53 \\
\hline Trading days & 2,735 & 2,735 & 2,735 \\
\hline Total & $79,035.66$ & $100,044.69$ & $179,080.35$ \\
\hline
\end{tabular}

Note. The table reports summary statistics for the nominal volume of collateral in MTS general and special repo transactions over the period April 1, 2003 to December 6, 2013.

specialness is generally considered as a signal of greater "market desirability" or the relatively scarce supply of the specific instrument used as collateral in the repo contract. In this paper, we provide novel empirical evidence on Italian government bonds and develop a comprehensive model for explaining repo specialness. We also observe that the degree of specialness changes over time and across bonds, and often exhibits some recurrent patterns that are correlated with the bond auction cycles.

The first theoretical underpinning of our empirical investigation on Italian government bonds repo specialness is provided by the model developed by Duffie (1996) for the U.S. repo market. Duffie (1996) explains that specialness can arise when collateral owners are inhibited from supplying the collateral in repos because of legal/institutional requirements or frictional/opportunity costs. Most of the existing literature testing Duffie's model of repo specialness focuses on U.S. government bond special repos. Jordan and Jordan (1997) empirically test Duffie's model using data on overnight repos that have U.S. treasuries as collateral. They find that the lower supply of collateral for repos (measured by higher auction tightness and lower ownership by dealers) causes higher repo specialness. Several other studies investigate the U.S. Treasury repo market (see for instance Fisher, 2002; Graveline \& McBrady, 2011; Keane, 1995; Krishnamurthy, 2002; Moulton, 2004; and Sundaresan, 1994). They explain the degree of specialness using longterm treasury supply as the main explanatory variable, but also control for auction cycles, liquidity demand, on- and off-the-run status of the bonds, and some other risk factors. More recently, D'Amico, Fan, and Kitsul (2018) focus on the effects of Federal Reserve Board (FED) programs on U.S. overnight special repo rates during the period
2009-2013 by looking at the amounts of treasuries purchased and sold by the FED. ${ }^{2}$

Few papers have studied repo specialness in the European markets. Buraschi and Menini (2002) find that long-term German sovereign special repos overestimate the future relative scarcity value of bonds on special because of the existence of time-varying liquidity risk premiums. Corradin and Maddaloni (2017) analyse the Italian sovereign overnight repo market over the short period October 2009 to July 2012, which includes the European sovereign debt crisis (ESDC). They show that the European Central Bank (ECB) interventions, in particular, the outright purchases of government bonds in the Securities Markets Programme (SMP) framework, had an important effect on the repo markets by affecting the supply of collateral.

We look at a much longer sample period, from April 2003 to December 2013, covering the tranquil period of April 2003-August 2007; the 2007-2009 global financial crisis (GFC); the 2010-2012 ESDC; and the post-crisis period of February 2012-December 2013. We use a dataset of intraday bond data and repo daily data from MTS. This allows us to run a comprehensive test of Duffie's (1996) theoretical predictions for the Italian government bond repo market, to examine whether a larger set of risk factors than those indicated by Duffie's model have affected specialness over this extended period and whether/how the effects of some key variables on specialness have changed over time. ${ }^{3}$

Furthermore, our empirical work analyses three different repo-term contracts: overnight (ON1), tomorrow-next (TN), and spot-next $(\mathrm{SN})$ repos. We provide a detailed analysis of the dynamics of specialness for these three different repo terms over the Italian government bonds' auction cycles. This comparative analysis has never been reported in either U.S. or European repo studies and it reveals some interesting differences. We find that repo contracts on Italian BTPs exhibit persistent and significant patterns that are related to the reopening of existing bond issues. With a reopening auction on day $T$, the amount of bonds outstanding increases starting from the auction settlement date $T+2$ onwards. We observe that, on average, specialness tends to increase steadily for all repo terms from the announcement date of the reopening until a few days before the actual auction settlement date, and then it decreases. The effect of auctions on specialness tends to decrease over consecutive reopening auctions and it varies across bond maturities. The pattern of repo specialness around auctions varies across the three repo terms, being consistent with their contractual differences in the timing of collateral exchange and with higher short selling activity by dealers via reverse-repos ahead of auctions. Dealers hedge the risk they are about to acquire at auction by short selling similar securities in the secondary market before the auction. We define this behaviour as hedging the 
"winner's curse," which is the risk of bidding too aggressively at auction and thus being allocated too many bonds at a relatively low yield (Beetsma, Giuliodori, Hanson, \& de Jong, 2018). Short selling is implemented by initiating reverse repos. Dealers are willing to accept lower special rates in these trades and this leads to higher specialness just before auctions. Although Keane (1995), Lou, Yan, and Zhang (2013), and D'Amico et al. (2018) have provided some preliminary evidence for the link between U.S. overnight repos and the bond auction cycle, the mechanism has never been tested in such detailed manner as we do on the Italian repo market. Our findings confirm the limited risk-bearing capacity of primary dealers' hypothesis for explaining why secondary market yields increase in anticipation of a new debt auction and decrease after the auction (Beetsma, Giuliodori, de Jong, \& Widijanto, 2016; Fleming \& Rosenberg, 2007; Lou et al., 2013). ${ }^{4}$

In our empirical analysis of the drivers of the Italian government bond repo specialness, we estimate pooled regressions that include proxies for various factors, which may affect repo specialness, in particular collateral supply, collateral liquidity, and collateral risk exposure. In addition, we analyse the impact of repo liquidity and auction cycles on specialness. Our results support Duffie's (1996) theoretical prediction that bond supply is an extremely significant factor for explaining repo specialness. However, we also find that the realized volatility of bond returns (a proxy for information uncertainty), bond fire sales, and repo liquidity are additional significant explanatory variables. The impact of some factors on specialness changes before, during, and after the two crisis periods of 2007-2009 (GFC) and 2010-2012 (ESDC). We find that during the two crisis periods, the importance of the realized bond volatility increases. Bond fire sales appear significant only during the ESDC subperiod. Furthermore, we notice that the relationship between bond liquidity (measured by the bid-ask spread) and specialness is negative; more liquid bonds with lower bid-ask spreads tend to have lower specialness on average. This contradicts Duffie's (1996) prediction that more liquid bonds tend to have larger specialness than other similar bonds. Hence, our bond liquidity proxy seems to reflect changes in information uncertainty and speculative demand rather than just changes in bond market frictions, at least when used in pooled regressions. Higher information uncertainty and higher speculative demand increase bond bid-ask spreads, but they also increase the demand for special repos and therefore repo specialness. When we only consider cross-sectional effects, Duffie's (1996) prediction that bonds with higher liquidity (lower bid-ask spread) are traded more on special seems to be verified. Our comprehensive analysis appears therefore very relevant to understand how shocks on demand and supply of collateral and on the behaviour of Italian
Treasury dealers/traders in good and bad times can affect a major secured money market instrument.

The paper is organized as follows. Section 2 presents a description of our sample, some preliminary statistical analysis, and a study of the effects of bond auction cycles on repo specialness. Section 3 presents the empirical model and identifies the main determinants of repo specialness. Section 4 illustrates the empirical results. Section 5 summarizes the main contributions and findings of the paper.

\section{2 | DESCRIPTIVE ANALYSIS}

\section{1 | Special repo data selection}

A repo contract entails an agreement for selling the bond on the repo settlement date (first leg) and repurchasing it at a future date (second leg) that differs according to the "repo term" specified in the contract (see Table 2). We consider three types of one-day repo contracts in our analysis: ON1, TN, and SN. The ON1 repo contract is settled on the same date as it trades $(T)$ and the collateral is repurchased on the next business day $(T+1)$. The $\mathrm{TN}$ repo contract is instead settled at $T+1$ (one business day after the repo trade date), whereas the bond is repurchased at $T+2$. The $\mathrm{SN}$ repo is settled at $T+2$ (two business days after the repo trade date), whereas the bond is repurchased at $T+3$.

The repo counterparty that provides the collateralized loan is said to enter into a reverse repo contract: the bond purchased in the first leg of the transaction can be used either to take a short position or to cover an outstanding short position in that bond. The need to obtain temporary ownership of a given bond often motivates special repo contracts; the stronger the need for covering short positions in the bond, the lower its special repo rate. If a security is in strong demand, dealers/traders may be willing to offer "cheap" cash to get hold of this asset in the special repo market. In this case, special repo rates can fall close to zero or even become negative, so they can be far below the GC rate and the specialness can be particularly high. ${ }^{5}$

Figure 1 shows the time variation of the volume-weighted average specialness of Italian government bonds with

TA B L E 2 Description of repo terms

\begin{tabular}{lll}
\hline Repo Term & $\begin{array}{l}\text { Repo } \\
\text { Settlement Date }\end{array}$ & Repurchase Date \\
\hline Overnight (ON1) & $T$ & $T+1$ \\
\hline Tomorrow Next (TN) & $T+1$ & $T+2$ \\
\hline Spot Next (SN) & $T+2$ & $T+3$ \\
\hline
\end{tabular}

Note. $T$ represents the day when the repo contract is traded on the MTS. The repo settlement date is the date when the bond collateral is sold by the repo buyer/borrower to the repo seller/lender. 


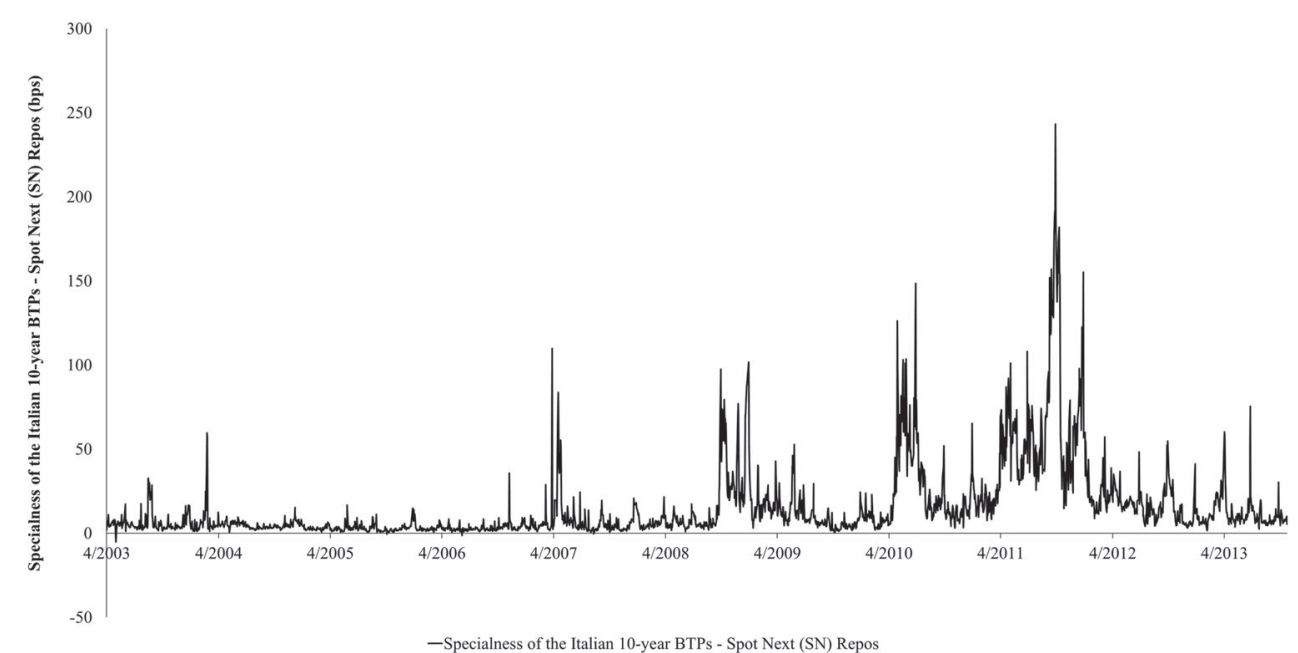

F I G URE 1 Degree of specialness of Italian BTPs with 10-year residual maturity. Volumeweighted average specialness (measured in basis points, bps) for spot-next (SN) special repos on Italian BTPs with 10-year residual maturity over the period from April 1, 2003 to December 6, 2013 10-year residual maturity used as collateral in $\mathrm{SN}$ special repos. We observe that often specialness is low (i.e., general and special repo rates are very close). However, there are times - for instance during the GFC and the ESDC-when specialness is very large, reaching up to 250 basis points (i.e., the special repo rate is much lower than the GC rate). In addition, specialness is characterized by several peaks throughout the sample period, which are often associated with reopening of auctions.

The aim of this paper is to explain how the repo specialness for Italian government bonds changes over time for different repo terms and different collateral maturities. We analyse a large sample of repo contracts that use Italian government bonds as collateral. Bond and repo data are extracted from the MTS Time Series database. Our sample covers the period from April 1, 2003, the first date available on this dataset, to December 6, 2013. The MTS repo platform is the leading market venue for repo contracts collateralized by Italian government bonds. The MTS repo data provide daily aggregate information on transacted nominal amounts, buyer-initiated (repo) volumes, seller-initiated (reverse repo) volumes, and total number of trades. This information is available for special or GC repos, each repo term (ON1, TN, or SN), and for each bond used as collateral for the repo transaction (identified by its unique ISIN code). The MTS bond data contains all intraday updates to prices and sizes of the best three bid and ask quotes. In addition, for each bond, we have daily prices and yields (sampled at 5:00 p.m. Central European Time-CET), modified duration, ${ }^{6}$ and number of daily trades. Other information about the specific characteristics of the instruments-for example, issuance date, maturity date, coupon payment schedule, and so forth-are provided in separate bond reference files. Using the bonds' ISIN numbers, we match the repo market information with the bond market information. For further information on MTS intraday data, see Dufour, Stancu, and Varotto (2017) and references therein.
We select all repos on Italian BTP_simple, semi-annual, coupon-paying bonds with no optionalities or inflationlinked pricing components. We concentrate only on Italian sovereign repos because of the large number of observations available on MTS for Italian GC and special repo rates. ${ }^{7}$ For each business day and each repoed bond, we collect the volume-weighted average ON1, TN, and SN GC Italian repo rate and subtract the corresponding volume-weighted average special repo rate. The resulting measure is the specialness. Bonds with non-zero specialness are said to be trading on special. Generally, we would expect non-negative specialness. However, asynchronous executions of GC and special repo trades may occasionally lead to negative specialness. Table 3 (Panels A and B) shows the summary statistics and distribution of specialness for the three different repo contracts over the whole sample period. There are 130 different bonds that are used as collateral for both the TN and $\mathrm{SN}$ repo contracts and 115 bonds used for ON1 repos. The SN repos have the largest number of observations $(127,585)$ followed by the TN and ON1 repos with 90,222 and 29,022 trades, respectively. In Table 3, we observe that the mean and median of specialness decrease when moving from ON1 to $\mathrm{TN}$ and to $\mathrm{SN}$ repos. The $\mathrm{ON} 1$ repo term has an average specialness of 33 basis points (bps), almost 20 bps higher than the TN average specialness and 25 bps higher than the SN average specialness. Moreover, if we consider the proportion of observations with specialness greater than 25 bps (see Table 3, Panel B), this is $38.26 \%$ for ON1 repos, but only $11.76 \%$ and $6.29 \%$ for $\mathrm{TN}$ and $\mathrm{SN}$ repos, respectively. ${ }^{8}$ Observations with negative specialness range from just $1.08 \%$ for ON1 repos to $2.29 \%$ for TN repos, and to $3.24 \%$ for $\mathrm{SN}$ repos. Specialness for ON1 repos has the largest standard deviation (47.85 bps), whereas the $\mathrm{SN}$ repo specialness presents the lowest standard deviation (20.64 bps).

In Figure 2, we consider all special repo trades and show how the median $\mathrm{ON} 1, \mathrm{TN}$, and $\mathrm{SN}$ repo specialness varies with respect to the residual maturity of the collateral. We 
TA B L E 3 Summary statistics and distribution of specialness for different repo terms

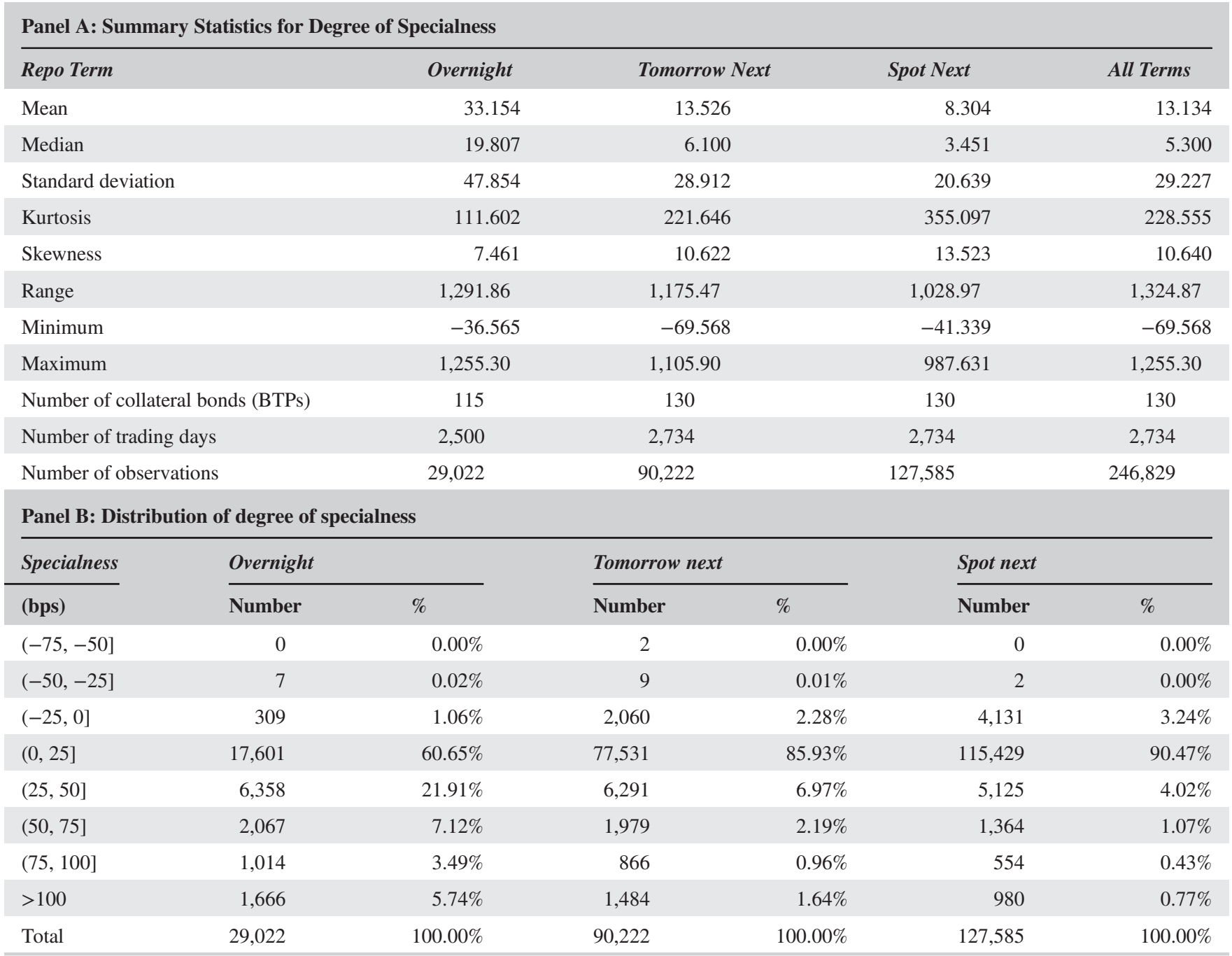

Note. The table reports summary statistics and distribution of specialness for repos on Italian BTPs over the period from April 1, 2003 to December 6, 2013. The specialness is measured in basis points (bps) and is the difference between the daily volume-weighted average Italian GC rate and the daily volume-weighted average special rate on a given Italian BTP. Panel A presents the summary statistics; Panel B reports the frequency of the distribution.

F I G URE 2 Specialness and residual maturity of collateral bonds. Median degree of specialness for overnight (ON1), tomorrow-next (TN), and spot-next (SN) repos plotted against the residual maturities of the collateral bonds. All BTPs used as collateral for repo trades on MTS are considered

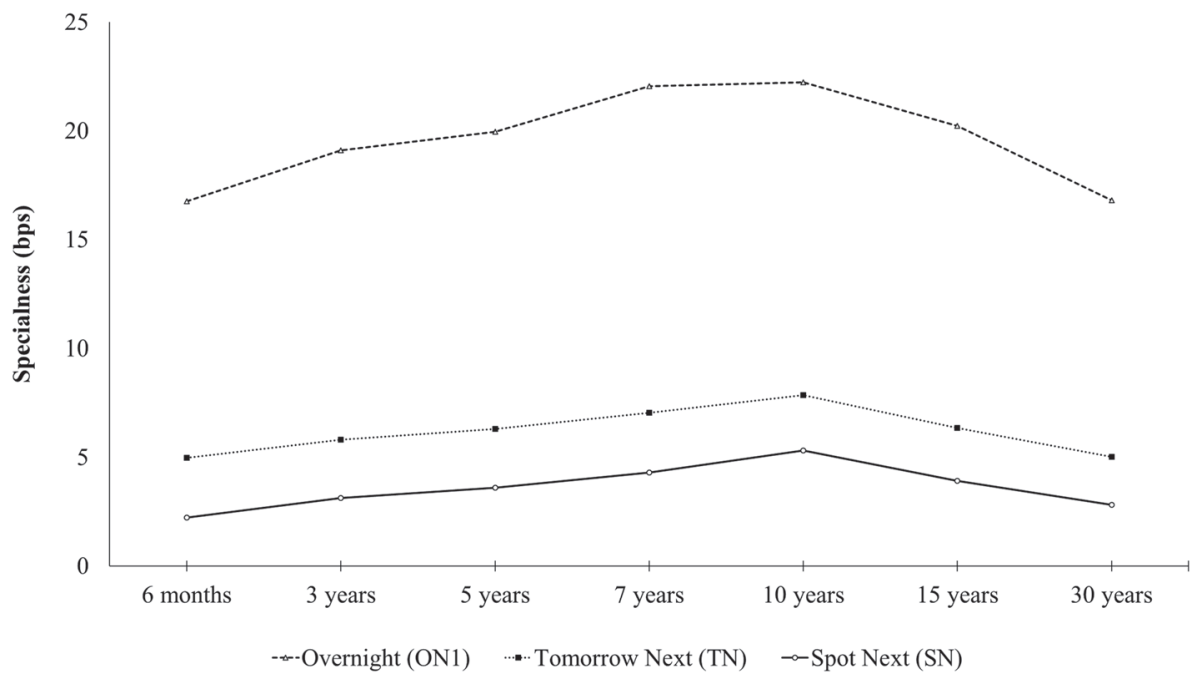


observe that (a) the specialness curve of the ON1 contract is much higher than the corresponding curves of the TN and SN contracts for all levels of collateral maturity, and (b) for each repo term, specialness increases monotonically with the collateral residual maturity, peaks at the 10-year maturity point, and then decreases for longer collateral maturities. This is consistent with a higher scarcity of the 10-year bonds.

The ON1 repo specialness is the highest on average among the three repo contracts. This finding is expected, as this is the contract with the shortest term. Often, traders urgently needing a particular bond have limited options available for securing it and, hence, are willing to lend cash at low rates in order to obtain the desired bond through an ON1 reverse repo transaction.

Next, we study tick-by-tick bond data, which are filtered implementing the sequence of steps described in Appendix B.

\subsection{Effect of auction cycles on specialness}

Furthermore, we retrieve information on primary market auctions, auction calendars, and all related communications from the Bank of Italy and the Italian Treasury websites. ${ }^{9}$ Table 4 reports the number of bonds issued via either primary ordinary market auctions or syndicate placements during the sample period for each maturity group; 83 out of 130 sample bonds are either first issued or have reopening auctions. Most of the bonds issued during our sample period have maturities of 3, 5 and 10 years. ${ }^{10}$

We use this information for a preliminary descriptive analysis of the effect of Treasury auctions on specialness. We expect Treasury auction cycles to have a strong influence

TA B L E 4 Number of bonds issued via primary ordinary auctions and syndicate placements and used in repo transactions

\begin{tabular}{|c|c|c|c|c|}
\hline \multirow{2}{*}{$\begin{array}{l}\text { Maturity } \\
\text { Group (years) }\end{array}$} & \multirow{2}{*}{$\begin{array}{l}\text { Issued } \\
\text { Bonds }\end{array}$} & \multicolumn{3}{|c|}{$\begin{array}{l}\text { Sample Bonds used as Repo } \\
\text { Collaterals }\end{array}$} \\
\hline & & Overnight & $\begin{array}{l}\text { Tomorrow } \\
\text { next }\end{array}$ & $\begin{array}{l}\text { Spot } \\
\text { next }\end{array}$ \\
\hline 3 & 26 & 32 & 37 & 37 \\
\hline 5 & 22 & 28 & 33 & 33 \\
\hline 10 & 20 & 36 & 41 & 41 \\
\hline 15 & 8 & 8 & 8 & 8 \\
\hline 30 & 7 & 11 & 11 & 11 \\
\hline Total & 83 & 115 & 130 & 130 \\
\hline
\end{tabular}

Note. The table reports the number of BTPs issued via primary ordinary auctions and syndicate placements, according to different repo terms and maturity groups, and used as collateral in repo transactions on the MTS over the period from April 1, 2003 to December 6, 2013. It also reports the total number of BTPs used as collateral in repo transactions recorded on the MTS over the same period (by maturity group and by repo term). on the degree of repo specialness as they affect the supply of collateral. We consider only ordinary auctions (and reopening auctions) and the syndicate placements, while we do not consider central bank exchange transactions and buybacks, given their marginal importance. ${ }^{11}$

It seems reasonable to expect no shortage of a particular bond for trading in the secondary market right after the bond has been issued. Thus, the repo specialness for this bond should be very low. However, as time passes, a larger amount of the issued bond is purchased by buyand-hold investors. Consequently, the availability of the bond for repo trading becomes lower and specialness increases. This pattern is observed at the first reopening auction, as well as at following reopening auctions, albeit to a lower extent. Moreover, the auction-cycle pattern of specialness changes according to the maturity of the bond collateral. Bonds with shorter maturities (3, 5, and 10 years) have more frequent reopening auctions (although a lower total number of reopening auctions for each bond) than longer-maturity bonds (15 and 30 years), which present reopening auctions more irregularly distributed over the longer life of the bond.

For each bond issue, we look at the first six consecutive reopening auctions across different bond maturities and repo terms. The largest effects of the auction cycle on specialness are observed for the shortest term, ON1 repos. Not only do ON1 repos reach the highest average specialness before reopening auctions compared with the other repo terms, but also their specialness starts increasing sooner than the specialness of $\mathrm{TN}$ and $\mathrm{SN}$ repos. ${ }^{12}$

As an example, in Figure 3 we consider the pattern of repo specialness around the first reopening auction of all 3-year BTPs issued during our sample period and for all three repo terms. We can observe that for all repo terms (ON1, TN, and SN), specialness tends to increase from the announcement date (A) of the reopening auction, always peaking before the auction settlement date $(R+2)$ and from there it decreases. The peak day changes according to the repo term. The average ON1 repo specialness remains high until 1 day before the settlement date when it reaches 70.93 bps. The average TN repo specialness displays a peak 2 days before the auction settlement date at a level of 64.59 bps and the average SN repo specialness peaks 3 days before settlement when it reaches 48.03 bps. We attribute this behaviour to the different timing of the collateral exchange for the three repo terms (see Table 2). In ON1 repos, the first leg of the repo (bond sale) is settled on the same day as the repo trade $(T)$ and the repurchase happens on the next business day $(T+1)$. In TN repos, both sale and repurchase of the collateral bond happen with a 1-day "delay" with respect to ON1 repos, whereas $\mathrm{SN}$ repos have a 2-day delay. 
F I G URE 3 Specialness and repo term effects at the first reopening auction after issuance for BTP with 3-year maturity. Average ON1, TN, and SN degree of specialness (measured in basis points, bps) over auction cycles for all 3-year maturity BTPs traded in both the primary and secondary market from April 1, 2003 until December 6, 2013. The auction cycle includes 3 days before auction date (i.e., auction announcement date), 2 days before auction date, 1 day before auction date, auction date, 1 day after auction day, and 2 days after auction day (i.e., auction settlement date, when the bond is delivered to primary dealers)

In advance of a reopening auction, primary dealers with limited risk-bearing capacity (Fleming \& Rosenberg, 2007) hedge the risk of the winner's curse (being allocated too many bonds at a low yield) by short-selling the alreadyissued bond. ${ }^{13}$ To do so, they enter into a special reverse repo. They lend cash to their counterparties and take the Treasury bond as collateral, which they then short sell in the secondary market. If they are allocated too many bonds at auction, they can reduce their exposure by covering their short position in the cash market and closing out the reverse repo by delivering the bond for the second leg of the repo transaction. The primary dealer hedging process is implemented by setting the second leg (collateral delivery and receipt of cash with interest) of the special reverse repo at the auction settlement date, when the additional bond supply becomes available to primary dealers. For example, if primary dealers hedge using a TN reverse repo, they enter into the contract 3 days before the auction settlement date. ${ }^{14}$ At this time, there will be an increase in the demand of TN reverse repos for the specific bond; its special repo rate will decrease and its specialness will rise. Consistently, we find that $\mathrm{TN}$ repo specialness on average peaks 2 days before the bond auction settlement date. For the same reason, ON1 repo average specialness peaks 1 day before the bond auction settlement date and SN repo average specialness peaks 3 days before the bond auction settlement date. ${ }^{15}$ This evidence is consistent with the following: (a) an increased demand for short positions in the newly issued bond tranche before the reissuance date; and (b) dealers' concern of the winner's curse leading to overestimating the amount of bonds they will be allocated at auction and hedging aggressively by initiating many reverse repos. The effect of primary Treasury dealers' hedging on repo contracts is also described by Lou et al. (2013) for the U.S. Treasury market. However, the regular pattern for specialness of different repo terms around auctions has never been fully explained and controlled for in previous repo studies. ${ }^{16}$

Moreover, we observe that the effect of auctions on specialness tends to vary both over reopening auctions and across bond maturities. Figure 4 plots the average SN repo specialness at subsequent reopening auctions. For each collateral maturity group, the auction cycle effect on specialness is higher for the first reopening auction and then it gradually decreases over subsequent auctions. With a larger amount of bond outstanding, the risk of collateral scarcity decreases and this leads to a lower degree of specialness. The SN repo specialness for bonds with 10-year maturity is on average higher than the specialness for 5- and 3-year bonds. This is consistent with the relationship between repo specialness and collateral maturity presented in Figure 2. Surprisingly, for the first two reopening auctions of the issue cycle, we observe peaks for the specialness of 15- and 30-year maturity bonds rising above the specialness of 10-year bonds. Thus, Figure 4 suggests high scarcity of the riskiest, longermaturity bonds around auctions possibly driven by strong hedging demand.

\section{3 | THE MODEL FOR DRIVING FACTORS OF SPECIALNESS}

In this and the following section, we examine which factors have an impact on repo specialness and how this impact changes over the 10-year period we have selected. 


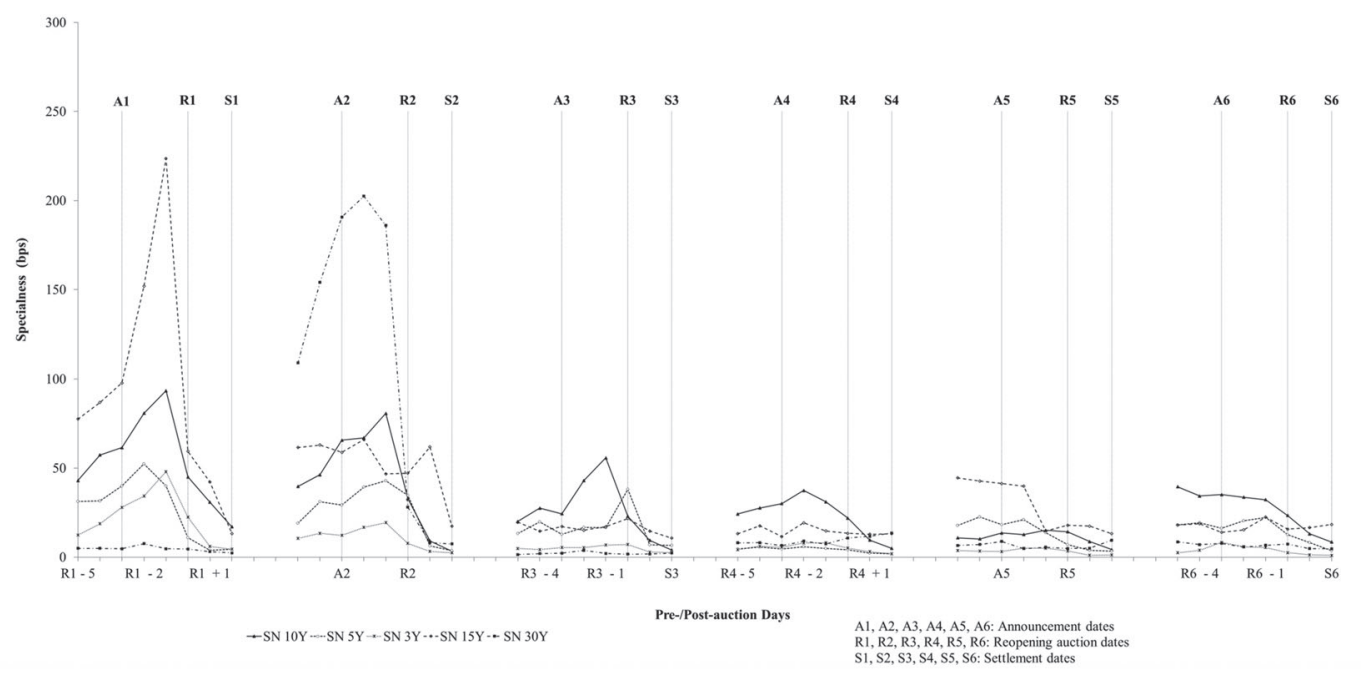

F I G U RE 4 Spot-next specialness at six consecutive reopening auctions for different bond maturities. Average spot-next repo specialness over auction cycles for bonds at different residual maturities (3, 5, 10, 15, and 30 years). Each reopening auction cycle includes 5 days before auction date, 4 days before auction date, 3 days before auction date (i.e., auction announcement date), 2 days before auction date, 1 day before auction date, auction date, 1 day after auction day, and 2 days after auction day (i.e., auction settlement date, when the bond is delivered to primary dealers)

First, we identify our dependent variable (repo specialness, Specialness ${ }_{i t}$ ) as the difference at time $t$ between the GC rate and the special repo rate for bond $i$ :

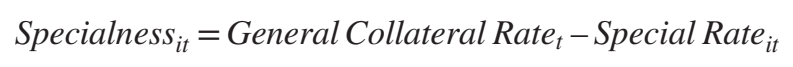

Next, we identify the main factors that affect specialness, construct proxy variables for each of these factors, and test empirically their relevance for the degree of specialness of bonds repoed in the marketplace.

\section{1 | Bond supply}

The supply of bonds to be used as collateral in repo transactions is one of the main factors for explaining specialness (Duffie, 1996; Jordan \& Jordan, 1997). If investors need temporary ownership of the bond but face restrictions in the collateral market, they may offer a low special rate (or even negative rates) to finance the inventory of bond holders. Sundaresan (1994) and Keane (1995) use the degree of "auction tightness" measured as the bid-to-cover ratio for on-therun bonds as a proxy for restrictions in bond supply. Another proxy used for supply conditions is the portion of newly issued on-the-run bonds that is allocated to dealers at auction with respect to buy-and-hold investors. The larger the portion allocated to buy-and-hold investors, the greater the probability of restrictions in supply and the higher the specialness of the collateral bonds. Krishnamurthy (2002) uses, instead, the total on-the-run amount outstanding for long-term debt instruments. These measures are well suited to the
U.S. Treasury repo market, but less so for a European one. In some European countries (such as Italy), the auction frequency is more irregular and Treasury auctions are subject to several reopenings, which alter the traditional definition of on-the-run bonds issued over a predetermined schedule as in the United States. Additional tranches of already issued BTPs can be re-auctioned several times after the first issuance; this implies that the amount outstanding of the on-therun bond increases over time with each reopening auction. To overcome the limitation of the existing proxies of bond supply, we use a secondary market measure of supply taken from the intraday quote updates recorded on MTS. We measure supply as the time-weighted average volume of collateral bonds available for sale at the top three levels of the ask price for each trading day. An inverse relation between specialness and supply of a bond is expected. As the supply of a bond decreases, the amount available for purchase is lower. When facing restrictions in supply, dealers needing temporary ownership of the bond must compete more vigorously in the repo market by offering lower special repo rates so specialness increases.

An additional measure of supply and demand in the collateral market is given by the bond trade imbalance, computed as the daily aggregate buyer-initiated volume minus the daily aggregate seller-initiated volume of repoed bonds (also known as cash trades) in MTS. ${ }^{17}$ A higher trade imbalance is a measure of net collateral buying pressure and indicates that the aggregate supply of the bond is lower than its aggregate demand. This condition may induce more traders who need the specific collateral to initiate reverse repos, for instance to cover their short positions. This may lead to lower special rates and higher specialness. Therefore, as the 
trade imbalance of a bond increases, its specialness increases too. The excess demand for bonds linked to short positions can also be captured by the repo net order flow-as in D'Amico et al. (2018)—which is measured as the daily aggregate buyer-initiated volume minus aggregate sellerinitiated volume of repo transactions. The daily aggregate buyer-initiated volume indicates the total amount of repos used for refinancing, whereas the daily aggregate sellerinitiated volume indicates the total amount of reverse repos that are usually associated with short selling. Thus, this variable should be inversely related to repo specialness.

\section{2 | Bond fire sales and volatility}

A factor that has not been explored in the studies of European government bonds and repos is the fire sales of bonds. $^{18}$ To build this measure of extreme selling pressure, we construct daily rebalanced bond portfolios by maturity groups and define fire sales as extremely large negative net bond order flows on days with large negative bond returns. The fire sales proxy is equal to the portfolio's relative trade imbalance when both the portfolio's relative trade imbalance and returns are below the $5^{\text {th }}$ percentiles of their respective distributions; otherwise, it is equal to zero. Further details on the construction of this measure and on the determination of the thresholds are provided in Appendix C.

Once we identify fires sales, we then study the relationship between portfolio fire sales and the specialness of the bonds included in the portfolio. Fire sales are generally caused by the very high liquidity needs of traders who sell their bond holdings in order to obtain cash. The massive selling pressure increases the supply of bonds. If bond traders have the option to choose which bonds to fire sell first from their inventories, then they would give lower priority to bonds trading on special in the repo market, as these can be used both for obtaining cheaper funding (i.e., by using them as collateral in low-interest special repos) and as preferred bonds for speculative trading. In this case, the fire sale pressure would hit "substitute" bonds and increase their supply (relatively to the special bond) while keeping the supply of the special bond relatively scarce and its demand high. This fire sale effect, which we call the "substitute effect," would be associated with a positive relationship between fire sale (large negative net order flows) and bond specialness. Namely, the bonds sold in a large fire sale have lower average specialness. However, on the other hand, if bond traders are constrained and the repo market for collateral borrowing is no longer accessible because of high credit risk, margins, haircuts, and so forth, then bond holders may prefer to sell the most valuable and desirable bonds, that is, those with high specialness. We call this effect the "high-value sale effect." This type of fire sales would be associated with a negative relationship between fire sale (large negative order flows) and specialness. Namely, the bonds sold in a large fire sale have higher average specialness. Which relationship prevails between fire sale and specialness remains, therefore, an empirical question.

Another factor that can help to explain specialness is the bond volatility. Higher volatility can increase bond speculative demand and short positions in Treasuries that need to be covered with higher amounts of reverse repos. Ultimately, this may lead to greater specialness. We measure bond volatility using the intraday bond-realized volatility, given by the total sum of squared log bond returns computed using tick-by-tick mid prices (average of best bid and ask prices) during each day, as observed at each quote update in the consolidated bond order book. We use a 20-day rolling average of realized volatility to reduce the effect of large outliers.

\section{3 | Bond interest rate risk and liquidity}

Given the collateralized nature of the repo transaction, a repo lender can suffer losses if the original value of the BTP used in the special repo drops because of increasing interest rates. A higher special repo rate would be required to compensate for the higher potential risk of the collateral bond. As most of the special repos have coupon bonds as collateral, we prefer using the bond modified duration instead of the bond maturity as a measure of collateral interest rate risk. Each bond trades at different prices throughout the day, therefore we measure the modified duration on the basis of the average volume-weighted price of the bond on that day. We expect that the higher the modified duration of a bond, the higher its interest rate risk, and the higher the special repo rate.

Duffie's (1996) model predicts that given two bonds that are otherwise identical, the more liquid bond trades more on special. Liquid bonds are more often shorted and are in greater demand as collateral in repo transactions. Speculators who want to short a bond would in fact choose the most liquid one in a selected category, as it would be easier for them to repurchase it when they need to close their short position. We look at the bond's relative bid-ask spread (Bond BAS), which is measured as the daily time-weighted average bond bid-ask spread. The bond bid-ask spread can capture however two possible types of effects. On the one hand, the smaller the bid-ask spread, the more liquid the bond and the higher its specialness. On the other hand, a higher bid-ask spread can be caused by higher information asymmetry, rather than only higher illiquidity. Information asymmetry drives speculative demand, leading to higher demand for reverse 
repos and an increase in specialness. In summary, our measure of relative bid-ask spread can have a different impact on specialness, depending on whether it is mainly driven by illiquidity or information asymmetry. We also control for the bond's on-the-run and first off-the-run status. An on-the-run bond should be in greater demand; thus, it should present lower special rates and a higher degree of specialness.

\subsection{Repo trades, quantity, and order flows}

Furthermore, we control for some key repo market characteristics, namely, the number of repo trades and the total daily amount of bond face value sold as repo collateral in special repos. This latter volume-based measure of repo demand includes both repo and reverse repo transactions. We expect that as the number of daily repo trades for a given bond goes up, its specialness increases as well. In addition, we expect a downward sloping demand curve; when the amount of a given repoed bond increases, its repo specialness decreases. We also construct another proxy for demand-pressure in the repo market, the repo net order flows, defined as the difference between the buyer-initiated volume of repos and seller-initiated volume of reverse repos.

\section{5 | Auction cycles, types of repo contracts, and ECB interventions}

In addition, we control for the effect of auction cycles discussed in Section 2.2, using dummies for each day of the auction cycle, from 3 days before the auction (announcement date) to 2 days after the auction (settlement date). ${ }^{19}$ These dummies are differentiated with respect to each repo contract term (ON1, TN, and SN). We expect the collateral to be in high demand (hence trading on special) from around the auction announcement date until 3,2, or 1 day before the auction settlement for the $\mathrm{SN}, \mathrm{TN}$, and $\mathrm{ON} 1$ repos, respectively (see Section 2.2).

Moreover, we include dummy variables for the different repo-term contracts that control for the average difference in repo specialness among the three types. As explained in Section 2.1, we expect repo specialness to be higher for ON1 repos, followed by TN and SN repos.

Finally, Corradin and Maddaloni (2017) show the importance of controlling for the effect of the SMP. In particular, the second "activation period" of the SMP has mainly involved the outright purchases of Italian bonds by the ECB. This has reduced the number of Italian bonds available for trading in the secondary market and may have resulted in lower special rates and greater specialness. Therefore, we include a dummy variable that controls for this SMP second activation period. $^{20}$

\section{6 | Model specification}

We estimate the following pooled regression model:

$$
\begin{aligned}
& \text { Specialness }_{i t}=\alpha_{i}+\beta_{1} \text { Bond Supply }_{i t-1} \\
& +\beta_{2} \text { Bond Trade Imbalance }_{i t-1} \\
& +\beta_{3} \text { Bond Fire Sales }_{i t-1} \\
& +\beta_{4} \text { Bond BAS } S_{i t-1} \\
& +\beta_{5} \text { Bond Modified Duration }_{i t-1} \\
& +\beta_{6} \text { Bond Realized Volatility }_{i t-1} \\
& +\beta_{7} \text { Repo Quantity }_{i t-1} \\
& +\beta_{8} \text { Repo Trades } \text { it }-1 \\
& +\beta_{9} \text { Repo Net Order Flow }{ }_{i t-1} \\
& +\beta_{10} \text { On-the }- \text { run }_{i t} \\
& +\beta_{11} \text { Off - the }-\operatorname{run}_{i t}+\beta_{12} S M P_{t} \\
& +\gamma_{m 3} R m 3_{i t}+\gamma_{m 2} R m 2_{i t}+\gamma_{m 1} R m 1_{i t}+\gamma_{0} R 0_{i t} \\
& +\gamma_{p 1} R p 1_{i t}+\gamma_{p 2} R p 2_{i t}+\delta_{1} A 1_{i t}+\delta_{2} A 2_{i t} \\
& +\theta_{1} T N_{i t}+\theta_{2} S N_{i t}+\varepsilon_{i t}
\end{aligned}
$$

Because some bonds may be transacted more on special than others, especially if they have been targeted by particular trading strategies, we control for bond fixed effects. ${ }^{21} \mathrm{We}$ also include dummies for SN and TN contracts. $\alpha_{i}$ indicates a different intercept for each bond used as collateral in an ON1 repo. We use OLS with clustered standard errors (by bond and by type of repo contract). ${ }^{22}$ The explanatory variables are all lagged to avoid potential endogeneity problems. These variables are described in Section 3 and summarized below into six categories.

- Proxies of collateral scarcity:

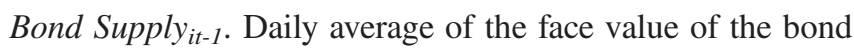
available for purchase at the top three levels of the ask side for bond $i$ on day $t-1$. $\beta_{1}$ is expected to be negative.

Bond Trade Imbalance $_{i t-1}$. Daily buyer-initiated volume less seller-initiated volume for bond $i$ on day $t-1 . \beta_{2}$ is expected to be positive.

Bond Fire Sales $_{i t-1}$. This is a truncated variable and it is equal to the relative trade imbalance on day $t-1$ of the residual maturity portfolio which bond $i$ belongs to. The variable takes a non-zero value only when the relative trade imbalance is lower than the $5^{\text {th }}$ percentile of its distribution and also when the equally weighted portfolio return for all bonds with the same residual maturity as bond $i$ on day $t-1$ is below the $5^{\text {th }}$ percentile of its distribution. $\beta_{3}$ is expected to be positive if the substitute effect dominates or negative if the high-value sale effect dominates. 
- Proxies of collateral liquidity:

Bond $B A S_{i t-1}$. Daily time-weighted average of the relative bid-ask spread of bond $i$ on day $t-1 . \beta_{4}$ is expected to be negative if the variable mainly reflects frictional trading costs, or positive if it mainly reflects information asymmetry and speculative demand.

- Proxies of collateral riskiness:

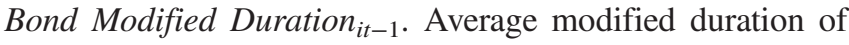
bond $i$ on day $t-1 . \beta_{5}$ is expected to be negative.

Bond Realized Volatility Vit-1 $_{\text {. Sum of squared returns over }}$ a 20-day rolling window for bond $i$. Returns are computed using tick-by-tick mid-prices during each day $t-1$, observed at each quote's update in the consolidated bond order book. $\beta_{6}$ is expected to be positive.

- Proxies of repo liquidity:

Repo Quantity $_{i t-1}$. Sum of face value of bond $i$ sold as repo collateral on day $t-1 . \beta_{7}$ is expected to be negative.

Repo Trades it -1 . Number of repo transactions on day $t-1$ involving bond $i$ as repo collateral. $\beta_{8}$ is expected to be positive.

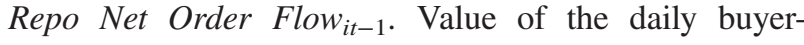
initiated volume minus seller-initiated volume of special repos for bond $i$ traded on day $t-1$. The buyer-initiated volume corresponds to the volume of repos (or collateral sold via repo trades), whereas the seller-initiated volume corresponds to the volume of reverse repos (or collateral purchased via repo trades). $\beta_{9}$ is expected to be negative.

- Dummies for on-the-run and off-the-run:

On-the-run ${ }_{i t}$. Dummy is equal to 1 if bond $i$ is an on-the-run bond on day $t$ (within its residual-maturity group), or 0 otherwise. $\beta_{10}$ is expected to be positive.

Off-the-run $i t$. Dummy is equal to 1 if bond $i$ is the first off-the-run bond on day $t$ (within its residual-maturity group). $\beta_{11}$ is expected to be positive, as the bond is in relatively higher demand than other off-the-run bonds within the same maturity group.

- Dummies for SMP, auction cycle effects, and type of repo contract:

$S M P_{t}$. Dummy to control for the SMP intervention period with ECB's purchases of Italian sovereign bonds. The period starts on August 8, 2011 and ends on February 10, 2012. ${ }^{23}$ If day $t$ is included in this period, then the dummy variable takes the value of $1 ; 0$ otherwise. $\beta_{12}$ is expected to be positive. $^{24}$

R_0 it $_{\text {. Dummy vector }}\left(R \_O_{O N 1} i t, R \_O_{T N} i t, R \_O_{S N} i t\right)$. Each dummy is equal to 1 if day $t$ is the auction date for a bond $i$ repoed in an $\mathrm{ON} 1, \mathrm{TN}$, or $\mathrm{SN}$ contract, respectively. The dummy is 0 otherwise.

$\mathbf{R m} 3_{\text {it, }}, \mathbf{R m} 2_{\mathbf{i t}}, \mathbf{R m} \mathbf{1}_{\mathbf{i t}}$. Dummy vectors $\left(R \_m 3_{\text {ON1 }} i\right.$, $\left.R \_m 3_{T N} i t, R \_m 3_{S N} i t\right),\left(R \_m 2_{O N 1}\right.$ it $, R \_m 2_{T N} i t, R \_m 2_{S N}$ it $)$, $\left(R \_m l_{O N 1}\right.$ it $R \_m l_{T N}$ it,$\left.R \_m l_{S N \text { it }}\right)$. Each dummy is equal to 1 if day $t$ is 3,2 , or 1 day, respectively, before the auction date in the primary market for a bond $i$ repoed in an ON1, $\mathrm{TN}$, or SN contract. The dummies are 0 otherwise. $\mathbf{R m} \mathbf{3}_{\mathbf{i t}}$ represents the announcement date of the bond auction.

$\mathbf{R p} 1_{i t}, \mathbf{R p} 2_{i t}$. Dummy vectors $\left(R \_p 1_{O N 1} i t, R \_p 1_{T N} i t\right.$, $\left.R \_p 1_{S N i t}\right),\left(R \_p 2_{O N 1}, R \_p 2_{T N} i t, R \_p 2_{S N i t}\right) . \mathbf{R p} \mathbf{1}_{i t}$ dummies are equal to 1 if day $t$ is the day after the auction for a bond $i$ repoed in an $\mathrm{ON} 1, \mathrm{TN}$, or $\mathrm{SN}$ contract, respectively; 0 otherwise. This is the date of the supplementary auction reserved for specialists. ${ }^{25} \mathbf{R p} \boldsymbol{2}_{i t}$ dummies are equal to 1 if day $t$ is 2 days after the auction in the primary market for a bond $i$ repoed in an $\mathrm{ON} 1, \mathrm{TN}$, or SN contract respectively; 0 otherwise. This is the auction settlement date.

$\mathbf{A} 1_{i t}$ and $\mathbf{A} 2_{i t}$. Dummy vectors $\left(A 1_{O N 1 ~ i t}, A 1_{T N i t}, A 1_{S N ~ i t}\right)$, ( $A 2_{\text {ON1 }}$ it $\left.A 2_{T N} i t, A 2_{S N} i t\right)$ indicate, respectively, the cycle periods for the first and second auction reopenings after the first issuance of a bond $i$ repoed in an $\mathrm{ON} 1, \mathrm{TN}$, or $\mathrm{SN}$ contract, respectively. They take value 1 if day $t$ corresponds to any of the days included in the relevant auction cycle (i.e., from 3 days before to 2 days after the reopening auction); 0 otherwise.

$T N_{i t}, S N_{i t}$. Dummies controlling for the type of repo contract. Each dummy is equal to 1 if a bond $i$ on day $t$ is repoed in a $\mathrm{TN}$ or $\mathrm{SN}$ contract, respectively, and 0 otherwise. ON1 is used as reference repo contract. Both $\theta_{1}$ and $\theta_{2}$ are expected to be negative with $\theta_{1}>\theta_{2}$.

Table 5 reports the sample summary statistics for all the independent variables. Across all repo contracts, the collateral bond has an average supply of $€ 68$ million, an average trade imbalance equal to $-€ 0.5$ million, a relatively high average bid-ask spread of 16 bps (but the median is half that), an average modified duration of about 5.4 years and a realized daily volatility of just $0.31 \%$. On average, 12.6 repo contracts are traded every day; the net order flow is around $-€ 16$ million (net reverse repos) and the total collateral face value of the traded repos is $€ 260.5$ million.

\section{4 | EMPIRICAL RESUTS}

\section{1 | Main results from the model}

We estimate the pooled regression model in Equation (2) for all repo contracts $(\mathrm{ON} 1, \mathrm{TN}$, and $\mathrm{SN})$ over the whole sample 
T A B L E 5 Summary statistics of independent variables for all repos (ON1, TN, and SN)

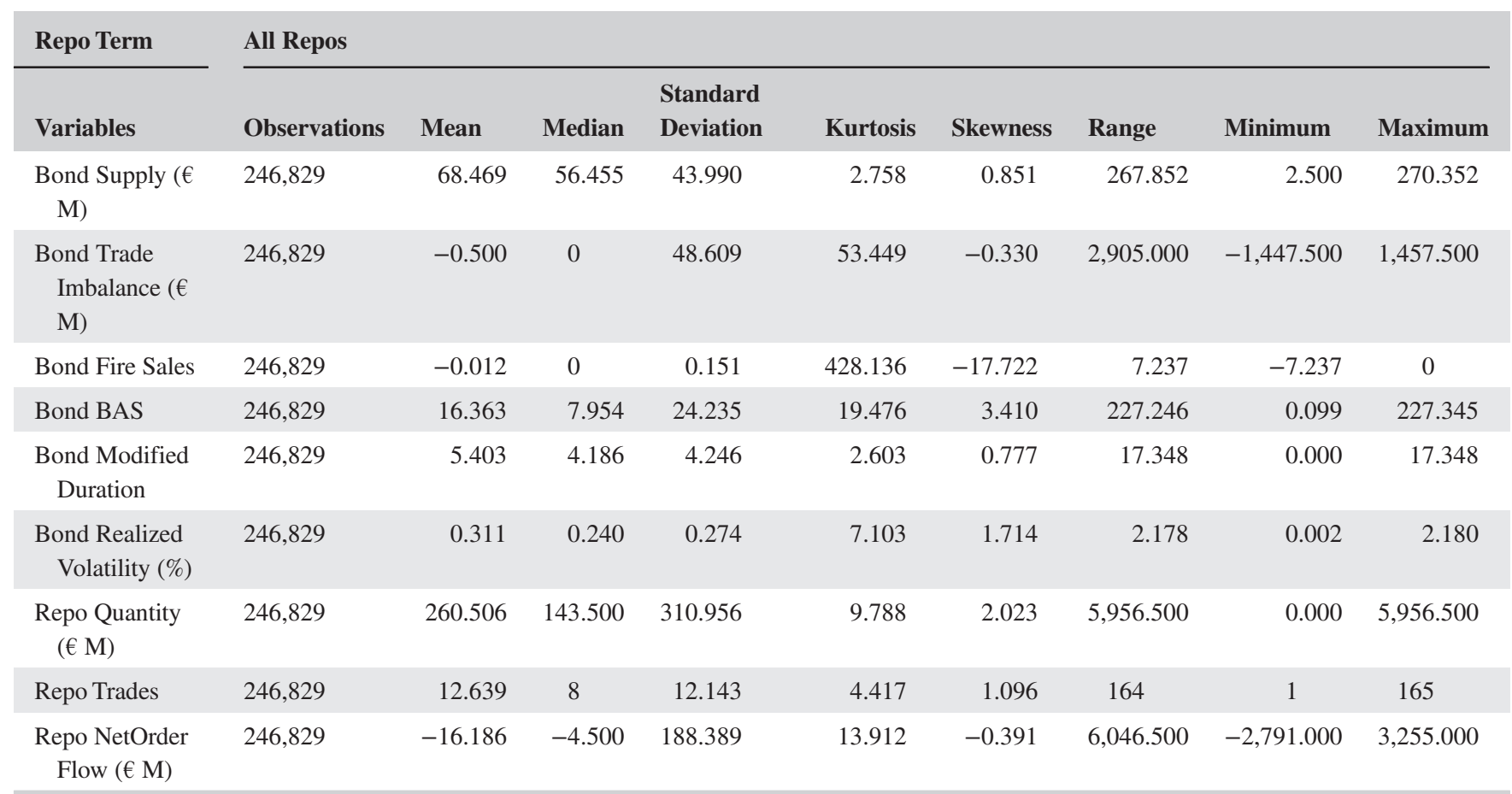

Note. This table presents summary statistics for all independent variables over all repos (overnight, tomorrow next, and spot next) and over the period April 1, 2003 to December 6, 2013. Bond Supply is measured as the time-weighted average volume of collateral bonds available for sale at the top three levels of the ask price for each trading day (the measurement unit is $€$ millions). Bond trade imbalance is equal to the difference between buyer-initiated volume and seller-initiated volume (measured in $€$ millions). Bond fire salesis the relative trade imbalance for residual-maturity portfolios and takes a value different from zero only if (a) the corresponding portfolio trade imbalance is below the $5^{\text {th }}$ percentile of its relative distribution and (b) the corresponding portfolio equally-weighted returns are below the $5^{\text {th }}$ percentile of the relative distribution of returns (truncated variable). Bond BAS is the daily time-weighted average bond's bid-ask spread. Bond modified duration is measured by the daily average bond's modified duration. Bond realized volatility is computed over a 20-day rolling window from daily log returns that are obtained as sum of squared returns based on tick-by-tick bond's mid-prices observed at each quote update in the bond's consolidated order book. Repo Quantity is measured in $€$ millions and it represents the nominal quantity of bonds sold as repo collateral. Repo Trades is the total number of daily repo transactions (involving the specific bond). Repo net order flow is equal to the difference between buyer-initiated volume and seller-initiated volume of special repo (measured in $€$ millions).

period (April 1, 2003 to December 6, 2013). The results are reported in Table 6.

The overall percentage of explained variation in repo specialness is $22.68 \%$. As expected, specialness increases with higher demand pressure for the collateral bond and decreases with higher bond supply. Lag Bond Trade Imbalance is significant, with the expected positive sign and with an economic impact on specialness of nearly $0.38 \mathrm{bps}$ for a one standard deviation increase. Lag Bond Supply presents a negative and highly significant coefficient. A one standard deviation increase in Lag Bond Supply induces a decrease of specialness of 3.74 bps. Lag Bond Fire Sales is also significant at the $1 \%$ significance level and presents a positive coefficient: the more extreme (i.e., the more negative) the fire sales, the lower the specialness. In terms of economic significance, a one standard deviation increase in Lag Bond Fire Sales induces an increase of $0.24 \mathrm{bps}$ in specialness. Extreme fire-selling activity seems to be associated therefore with lower specialness. When facing liquidity needs, traders sell bonds with lower specialness. Hence, the empirical evidence is consistent with the substitute effect rather than the high-value sale effect.
According to Duffie's (1996) predictions, specialness increases with bond liquidity, everything else being equal. Our proxy of collateral bond liquidity (Lag Bond BAS), however, seems to capture something different from the pure liquidity effect. ${ }^{26}$ This variable is strongly significant, both statistically and economically. However, a one standard deviation increase in Lag Bond BAS generates an increase (not a decrease) in specialness of $2.87 \mathrm{bps}$, ceteris paribus; information uncertainty attracts speculative demand, which in turn increases Italian government bond specialness.

In contrast, Lag Repo Trades seem to capture pure liquidity effects. The more frequently a bond is traded via repos, the more special it becomes, with a $1 \%$ level of statistical significance. For a one standard deviation increase in Lag Repo Trades, the economic impact on specialness is 4.43 bps. Repo trades may cluster on particular bonds that are more liquid and better-suited to execute trading strategies; their specialness will be higher on average. The Lag Repo Quantity is instead insignificant. However, there is high correlation between this variable and Lag Repo Trades (around 0.64). When the variables are used together in the regression, Lag Repo Trades partially subsumes the effect of 
TA B LE 6 Pooled regression Equation (2) results for the overall sample period

\begin{tabular}{|c|c|c|}
\hline $\begin{array}{l}\text { Dependent variable: Repo } \\
\text { specialness }\end{array}$ & \multicolumn{2}{|l|}{ All Repos } \\
\hline \multicolumn{3}{|c|}{ Clustered Standard Errors by Bonds and Repo Contracts } \\
\hline Independent variables: & Coeff. & $t$ stat. \\
\hline Intercept & $44.928^{* * *}$ & 30.96 \\
\hline Lag Bond Supply & $-84.949^{* * * *}$ & -10.68 \\
\hline Lag bond trade imbalance & $7.889^{* * *}$ & 4.50 \\
\hline Lag Bond Fire Sales & $1.576^{* * *}$ & 4.96 \\
\hline Lag Bond BAS & $0.118^{* * *}$ & 5.53 \\
\hline Lag Bond Modified Duration & 0.072 & 0.31 \\
\hline Lag Bond Realized Volatility & $9.543^{* * *}$ & 4.81 \\
\hline Lag Repo Quantity & 0.573 & 0.41 \\
\hline Lag Repo Trades & $0.365^{* * * *}$ & 7.23 \\
\hline Lag Repo Net Order Flow & $-5.813^{* * * *}$ & -3.94 \\
\hline On-the-run & 0.784 & 0.41 \\
\hline Off-the-run & 1.336 & 1.60 \\
\hline SMP & $16.418^{* * *}$ & 9.33 \\
\hline $\mathrm{Rm} 3_{\mathrm{ON} 1}$ & 9.033 & 0.96 \\
\hline $\mathrm{Rm} 2_{\mathrm{ON} 1}$ & $35.508 *$ & 1.92 \\
\hline $\mathrm{Rm} 1_{\mathrm{ON} 1}$ & $39.730^{* * *}$ & 2.92 \\
\hline $\mathrm{R} \_0_{\mathrm{ON} 1}$ & $32.187^{* *}$ & 2.38 \\
\hline $\mathrm{Rp} 1_{\mathrm{ON} 1}$ & $25.918^{* * *}$ & 2.25 \\
\hline $\mathrm{Rp} 2_{\mathrm{ON} 1}$ & $-16.087 *$ & -1.83 \\
\hline $\mathrm{A} 1_{\mathrm{ON} 1}$ & 26.694 & 1.59 \\
\hline $\mathrm{A} 2_{\mathrm{ON} 1}$ & 10.190 & 0.82 \\
\hline $\mathrm{Rm} 3_{\mathrm{TN}}$ & $10.193^{* *}$ & 2.04 \\
\hline $\operatorname{Rm} 2_{\mathrm{TN}}$ & $19.293^{* * *}$ & 2.81 \\
\hline $\mathrm{Rm} 1_{\mathrm{TN}}$ & $29.673^{* * * *}$ & 3.04 \\
\hline $\mathrm{R} \_0_{\mathrm{TN}}$ & $33.367^{* * * *}$ & 4.06 \\
\hline $\mathrm{Rp} 1_{\mathrm{TN}}$ & $-18.174^{\text {***** }}$ & -3.48 \\
\hline $\mathrm{Rp} 2_{\mathrm{TN}}$ & $-24.765^{* * *}$ & -4.34 \\
\hline $\mathrm{A} 1_{\mathrm{TN}}$ & $32.505^{\text {**** }}$ & 3.07 \\
\hline $\mathrm{A} 2_{\mathrm{TN}}$ & $18.928 *$ & 1.91 \\
\hline $\mathrm{Rm} 3_{\mathrm{SN}}$ & $9.730^{* *}$ & 2.22 \\
\hline $\mathrm{Rm} 2_{\mathrm{SN}}$ & $18.441^{* * * *}$ & 3.53 \\
\hline $\mathrm{Rm} 1_{\mathrm{SN}}$ & $31.017^{* * *}$ & 4.09 \\
\hline $\mathrm{R} \_0_{\mathrm{SN}}$ & -5.552 & -1.61 \\
\hline $\mathrm{Rp} 1_{\mathrm{SN}}$ & $-18.000^{* * * *}$ & -4.89 \\
\hline $\mathrm{Rp} 2_{\mathrm{SN}}$ & $-15.444^{* * * *}$ & -4.07 \\
\hline $\mathrm{A} 1_{\mathrm{SN}}$ & $24.493^{\text {**** }}$ & 3.54 \\
\hline $\mathrm{A} 2_{\mathrm{SN}}$ & $15.209^{* *}$ & 2.07 \\
\hline $\mathrm{TN}$ & $-19.179^{\text {**** }}$ & -27.53 \\
\hline
\end{tabular}

(Continues)
T A B L E 6 (Continued)

\begin{tabular}{lcc}
$\begin{array}{l}\text { Dependent variable: Repo } \\
\text { specialness }\end{array}$ & \multicolumn{2}{l}{ All Repos } \\
\cline { 1 - 1 } Clustered Standard Errors by & Bonds and Repo Contracts \\
\hline Independent variables: & Coeff. & $\boldsymbol{t}$ stat. \\
\hline SN & $-31.273^{* * * *}$ & -26.02 \\
Observations & & 246,462 \\
Bond Fixed Effects & & Y \\
Adjusted $R^{2}$ & & 0.2268 \\
\hline
\end{tabular}

Note. Pooled regression (Equation (2)) estimated with bond fixed effects and repo contracts' dummies for ON1, TN, and SN repos. Period: April 1, 2003 to December 6, 2013. T-statistics are computed using clustered standard errors by bond and type of repo contract. Variables' definitions are explained in Table 5. Bond Supply, Bond Trade Imbalance, and Repo Quantity are measured here in $€$ billions, whereas Repo Net Order Flow is measured in $€$ millions. On-the-run dummy $=1$ if bond is on-the-run; 0 otherwise. Off-the-run dummy $=1$ if the bond is the first off the run; 0 otherwise. SMP is a dummy equal to 1 if the day is within the period 08/08/2011-10/02/2012. Rm3, Rm2, and Rm1 are dummy vectors equal to 1 if the observed day is respectively 3,2 , or 1 day before an auction date (otherwise they are equal to 0 ); $R \_0$ is a dummy vector equal to 1 if the observed day is an auction date, 0 otherwise; $\mathrm{Rp} 1$ and $\mathrm{Rp} 2$ are dummy vectors equal to 1 if the observed day is, respectively, 1 or 2 days after an auction date otherwise they are equal to 0 . A1 and A2 are dummy vectors equal to 1 if the observed day is included in the first reopening auction cycle and second reopening auction cycle, respectively (cycle $=3$ days before to 2 days after reopening auction). TN and $\mathrm{SN}$ are dummies equal to 1 if the bond is repoed in a $\mathrm{TN}$ or SN contract, respectively, and 0 otherwise. ON1 is used as a reference repo contract.

**** indicates $1 \%$ significance;

** $5 \%$ significance;

* $10 \%$ significance.

Lag Repo Quantity. If we exclude Lag Repo Trades from the model, then we find that Lag Repo Quantity is highly significant and has a negative coefficient, as expected. Finally, the Lag Repo Net Order Flow is significant and displays the expected negative sign with a one standard deviation economic impact on specialness of -1.10 bps.

Next, we consider the proxies for collateral riskiness. The Lag Bond Realized Volatility is strongly significant and presents a positive coefficient. ForLag Bond Modified Duration, we do not find supporting evidence of a significant negative coefficient.

Interestingly, also the On-the-run and first Off-the-run dummies do not have a significant effect on specialness. Unlike the U.S. Treasury market, the supply of a newly issued bond can increase over time as new tranches of the same bond are issued. Thus, being recently issued (or onthe-run) has no particular importance in the Italian bond market. In contrast, the SMP dummy is significantly positive for all repo terms. When the ECB actively buys Italian bonds in the Italian Treasury market, these bonds get scarcer and more desirable, so their specialness increases. ${ }^{27}$ 
The auction cycle has a significant effect on repo specialness, as evidenced in Section 3.2. The coefficients of the pre-auction dummy vectors $\mathbf{R m} \mathbf{3}, \mathbf{R m} \mathbf{2}$, and $\mathbf{R m} \mathbf{1}$ for the different repo terms $\mathrm{ON} 1, \mathrm{TN}$, and $\mathrm{SN}$ are all positive, monotonically increasing, and significant (with only one exception, $\mathbf{R m} \mathbf{3}$ for ON1 is not significant). The coefficient of the auction day R_0 is also positive for ON1 and TN repos. The auction dummies become negative starting from the auction date (R_0) for SN, 1 day after the auction date (Rp1) for TN, and 2 days after the auction date (Rp2) for ON1. After the auction, dealers will realize whether they have fallen victim of the winner's curse. The special repo settlement days are strikingly aligned with the collateral bond auction settlement day allowing the dealer to offload overbought bonds via reverse repos. The repo remains on special until 1 day after the auction, until the day of the auction, and until 1 day before the auction for the ON1, TN, and SN repos, respectively. Finally, we observe that the influence of auction cycles decreases with the number of reopenings, and therefore with an increasing supply of the collateralized bond. For the longer-term TN and SN repos, the auction cycle dummy vectors A1 and A2 have positive and significant coefficients, but the coefficients of $\mathbf{A} \mathbf{1}$ are higher than the coefficients of $\mathbf{A 2}$. Also, the impact of $\mathbf{A 1}$ and $\mathbf{A 2}$ is greater for TN than for SN specialness. For ON1 specialness, the coefficient of the auction dummies $\mathbf{A 1}$ and $\mathbf{A 2}$ are also positive and decreasing, but not statistically significant. Finally, the repo contract dummies, TN and SN, are both significant and report a negative coefficient as expected (their specialness is on average lower than the ON1 specialness).

Furthermore, we perform a Shapley-Owen $R^{2}$ decomposition by category of regressors to assess their relative and distinct explanatory power. ${ }^{28}$ The categories of regressors have been identified in Section 3 as collateral scarcity, collateral liquidity, collateral riskiness, repo liquidity, dummies for onand off-the-run, auction cycle dummies, repo contract dummies, and the SMP dummy. The collateral liquidity category is the most influential category of regressors by marginal $R^{2}(15 \%)$, followed by the collateral riskiness category (about $8 \%$ ). The collateral scarcity and repo liquidity categories also present a sizable influence, with marginal $R^{2}$ of about $3 \%$ and $4 \%$, respectively. Among the control dummies, $\mathrm{TN}$ and $\mathrm{SN}$ have the greatest marginal explanatory power (9\% and 20\%, respectively), followed by SMP (13\%) and by the auction cycle dummies with marginal $R^{2}$ s of $7 \%$.

\section{2 | Results over different sample periods}

Next, we investigate whether the impact of the factors that explain the variation in specialness changes over time. We report the results in Table 7. We re-estimate our baseline model of repo specialness in Equation (2) over four distinct sub periods. First, we have the pre-crisis sub period that starts on April 1, 2003 and ends on August 8, 2007-this is a tranquil period before the GFC. ${ }^{29}$ During this pre-crisis period, the ECB implemented tight monetary policies and kept borrowing rates high. Next, we consider the GFC sub period, which runs from August 9, 2007 to December 31, 2009. During this period, dramatic changes in ECB policies are associated with substantial drops in borrowing costs. Third, we study the ESDC sub period, which starts on January 1, 2010 and ends on February 10, 2012. This period is characterized by several ECB interventions, mainly by the first activation period of the SMP for Greece, Portugal, and Ireland and by the second re-activation period for the SMP, characterized by the ECB's outright purchase of Italian and Spanish government bonds. ${ }^{30}$ Finally, we have the post-crisis sub period that starts on February 11, 2012 and ends on December 6, 2013.

The model has the highest explanatory power during the ESDC with an adjusted $R^{2}$ of $27.73 \%$. As reported in Table 7, Lag Bond Supply is highly significant only in the GFC and ESDC sub periods. In the ESDC sub period, the economic significance of Lag Bond Supply is particularly high reaching a -2.7 bps standard deviation $(S D)$ impact. It is likely that in this period, the variable also captures the additional effects on bond supply induced by the SMP purchases, which reduced the availability of bonds to be used as collateral in the secondary market.

Looking at Lag Bond Fire Sales, we note that the aggressive selling has a positive and significant coefficient during the ESDC subperiod, clearly indicating that large sales are associated with lower specialness and, hence, that the substitute effect prevails over the high-value effect. The economic significance of the variable is 0.48 bps $S D$ impact.

Lag Bond Realized Volatility presents the expected positive sign in all subsamples, but it is highly significant at the $1 \%$ level only in the two crisis subsamples (GFC and ESDC). Furthermore, we observe that Lag Bond Modified Duration has a significant effect on specialness in the precrisis and ESDC subperiods with the expected negative coefficient, whereas in the GFC and post-crisis subperiods, it carries an unexpected positive coefficient (it was insignificant in the all sample analysis of Table 6). When interest rate risk is very high due to serious tensions in European sovereign markets, there is lower demand for bonds with large modified duration, and thus these bonds trade less on special. The relation between modified duration and specialness is altered in the post-crisis subperiod. After the crisis, ceteris paribus, bonds with longer modified duration trade more on special.

We do not observe major differences across the subsample regressions (in Table 7) and the all-sample regression (in Table 6) for speculative demand and liquidity. When 
T A B LE 7 Pooled regression (Equation (2)) results over different sample periods

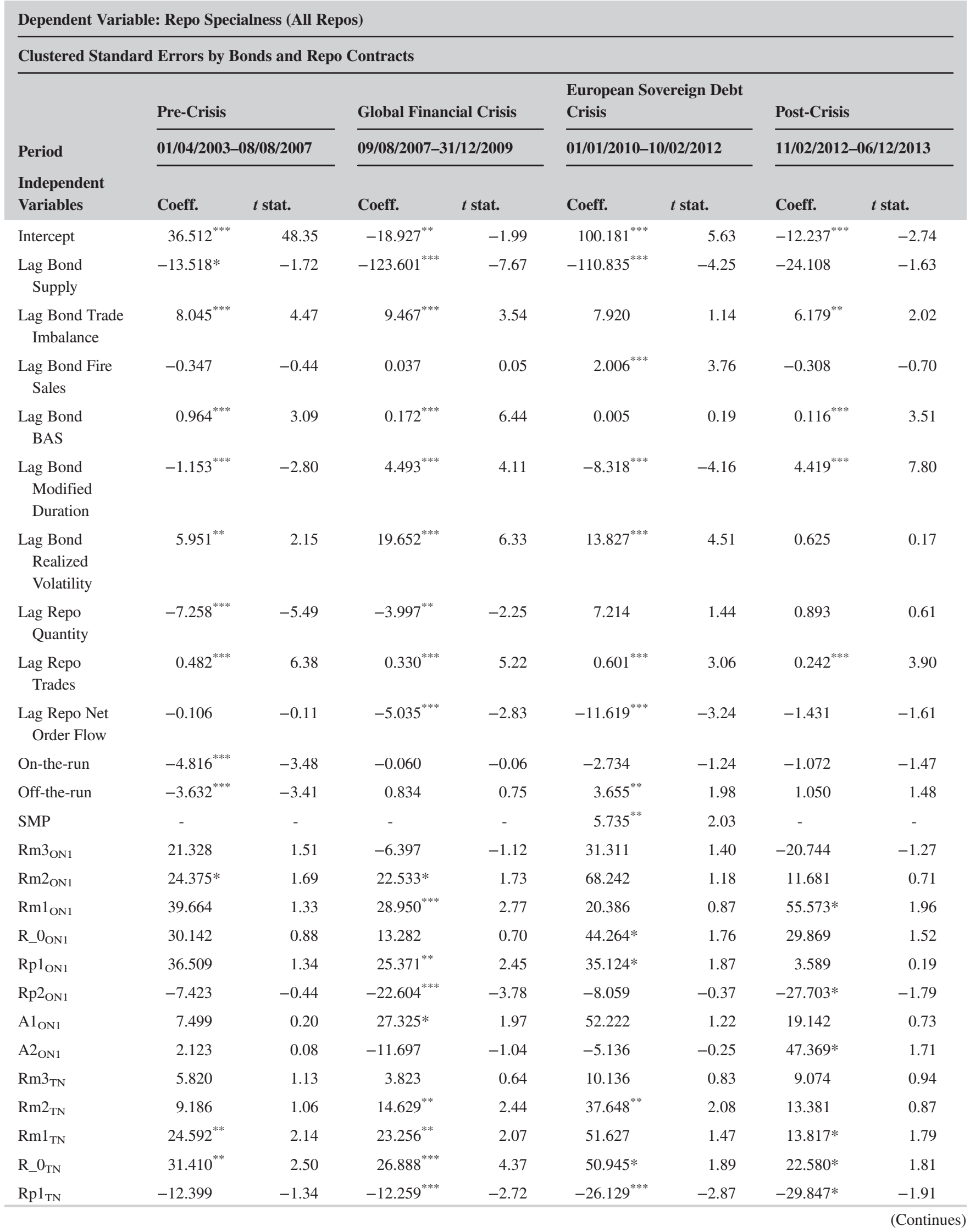


T A B L E 7 (Continued)

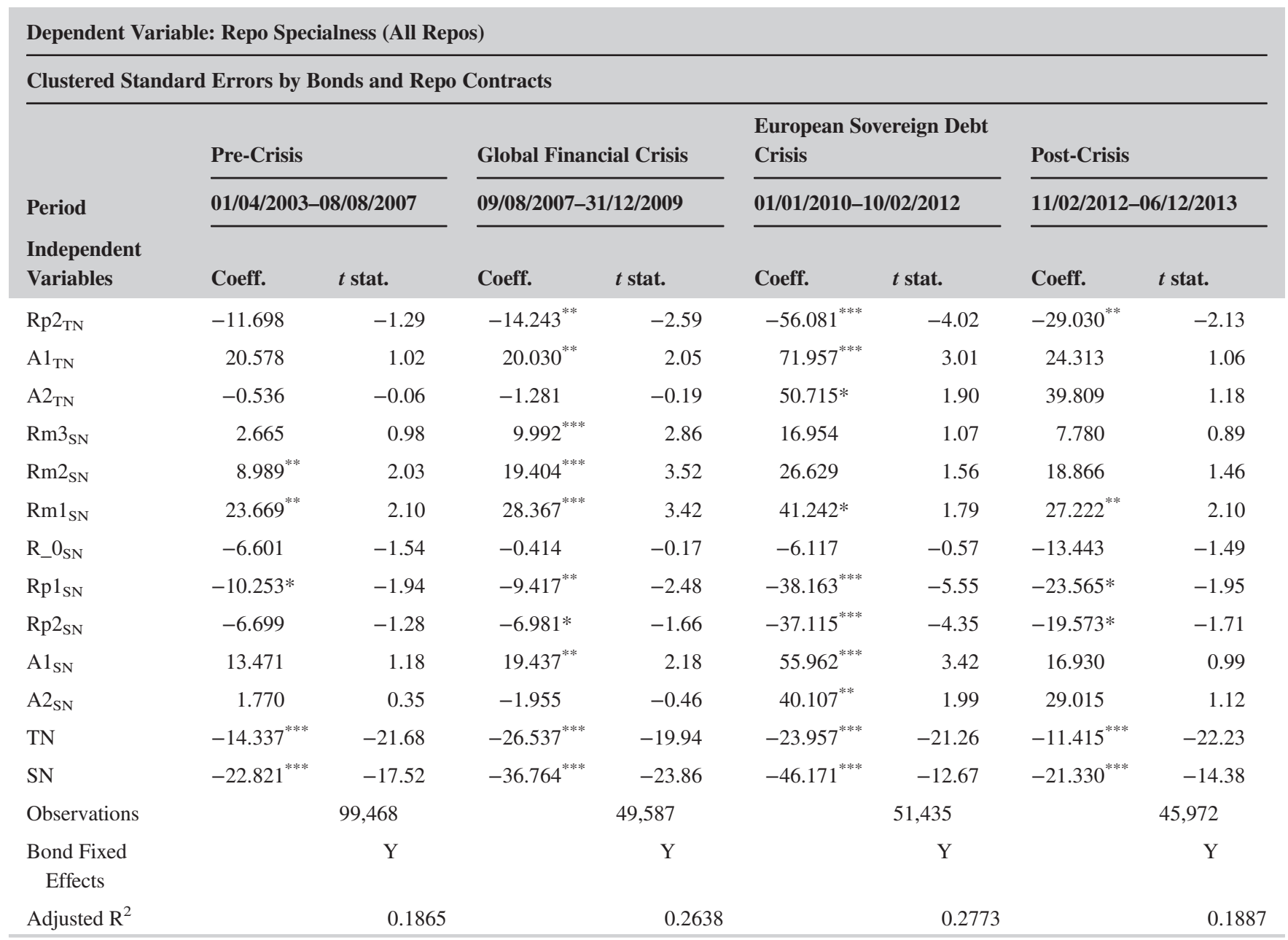

Note. Pooled regression (Equation (2)) results over four subperiods. First period: April 1, 2003 to August 8, 2007. Second period: August 9, 2007 to December 31, 2009. Third period: from January 1, 2010 to February 10, 2012. Fourth period: February 11, 2012 to December 6, 2013. Pooled regressions are estimated with standard errors clustered by bond and type of repo contract, bond fixed effects and repo contracts' dummies. Variables' definitions and measurements are explained in Tables 5 and 6.

**** Indicates $1 \%$ significance;

** $5 \%$ significance;

${ }^{*} 10 \%$ significance.

significant, the bid-ask spread is always positive. This clearly indicates that the bid-ask spread proxies speculative demand rather than liquidity. Meanwhile, liquidity is consistently captured by the variable Lag Repo Trades; in all subperiods the more frequently a bond is repoed, the higher its specialness. Lag Repo Net Order Flow, given by the difference between repo orders and reverse repo orders, always negatively affects the repo specialness, but more so during the ESDC period, with a peak economic impact of -2.25 bps. The effect during the ESDC is higher than the average economic impact of -0.91 bps recorded during the GFC subperiod. Ceteris paribus, a larger demand for reverse repos during the ESDC period, due to traders' willingness to speculate on Italian government bonds, determines a larger negative value for Lag Repo Net Order Flow; this is associated with lower repo rates and wider specialness.
Finally, the auction cycle and consecutive reopening auction dummies on specialness are more important over the GFC and ESDC subperiods. This suggests that during the two crisis periods, dealers were particularly concerned about the winner's curse in the bidding of reopened bond issues, so prompting more reverse-repos. Our result for the repo market is consistent with the findings of Lou et al. (2013) for the bond market.

\section{3 | Results by residual maturity subsamples}

As we have observed a positive relationship between repo specialness and bond residual maturity in Section 2.1, we now re-estimate our baseline regression model using residual maturity subsamples. Seven residual maturity groups are constructed: 6 months, $3,5,7,10,15$, and 30 years. ${ }^{31}$ For 


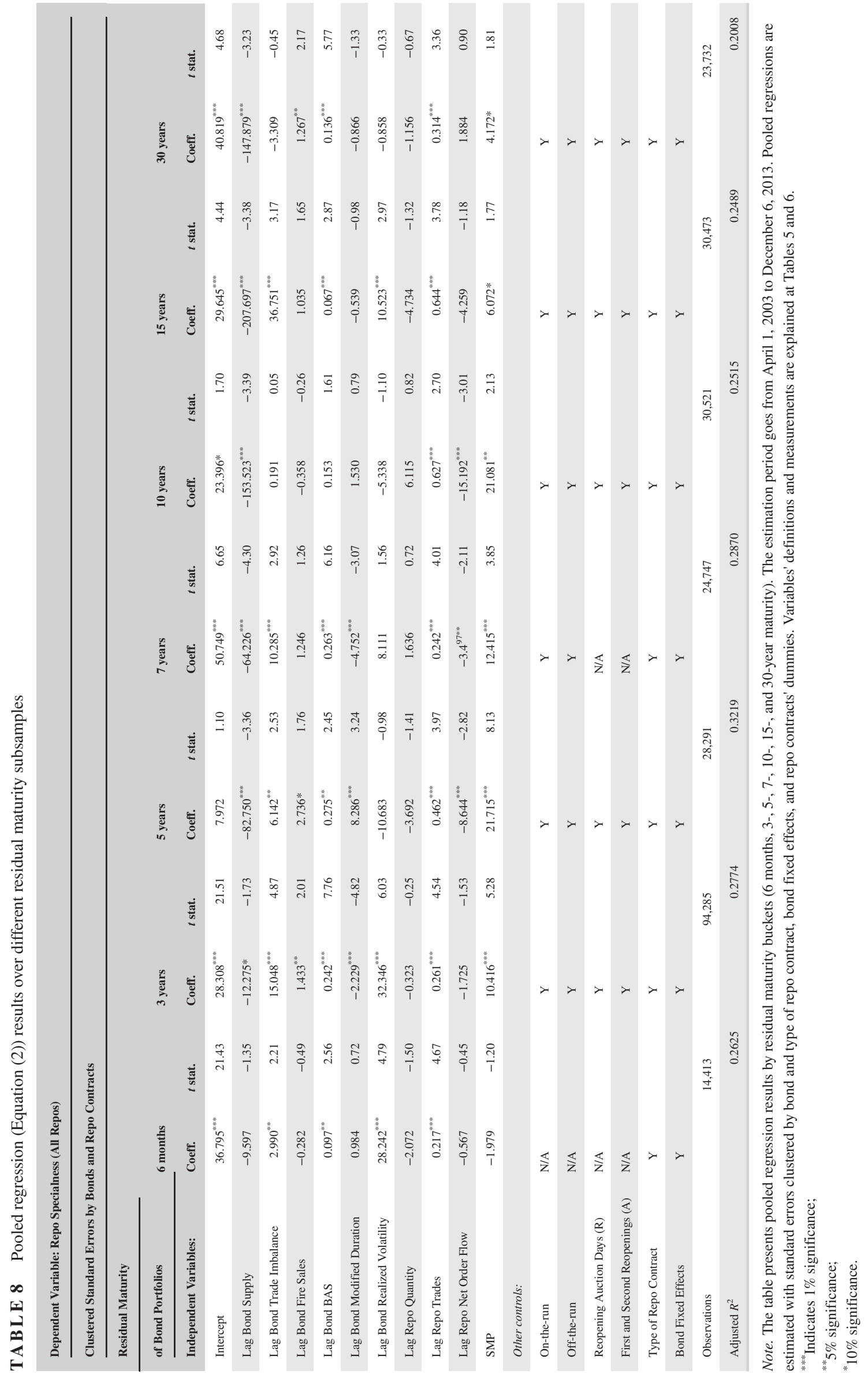


T A B L E 9 Regressions model estimated over different periods-between effects estimator

\begin{tabular}{|c|c|c|c|c|c|c|c|c|}
\hline \multicolumn{9}{|c|}{ Dependent Variable: Repo Specialness (All Repos) } \\
\hline \multirow{3}{*}{$\begin{array}{l}\text { Period } \\
\text { Independent } \\
\text { Variables: }\end{array}$} & \multicolumn{2}{|l|}{ Pre-Crisis } & \multirow{2}{*}{\multicolumn{2}{|c|}{$\begin{array}{l}\text { Global Financial Crisis } \\
09 / 08 / 2007-31 / 12 / 2009\end{array}$}} & \multirow{2}{*}{\multicolumn{2}{|c|}{$\begin{array}{l}\text { European Sovereign Debt } \\
\text { Crisis } \\
01 / 01 / 2010-10 / 02 / 2012\end{array}$}} & \multirow{2}{*}{\multicolumn{2}{|c|}{$\frac{\text { Post-Crisis }}{11 / 02 / 2012-06 / 12 / 2013}$}} \\
\hline & \multicolumn{2}{|c|}{$01 / 04 / 2003-08 / 08 / 2007$} & & & & & & \\
\hline & Coeff. & $t$ stat. & Coeff. & $t$ stat. & Coeff. & $t$ stat. & Coeff. & $t$ stat. \\
\hline Intercept & 7.412 & 1.41 & $50.896^{* * *}$ & 6.00 & 4.803 & 0.09 & $15.317^{* *}$ & 2.11 \\
\hline $\begin{array}{l}\text { Lag Bond } \\
\text { Supply }\end{array}$ & -25.624 & -0.71 & $-208.160^{* * * *}$ & -3.02 & -31.272 & -0.22 & $-233.988^{* *}$ & -2.65 \\
\hline $\begin{array}{l}\text { Lag Bond Trade } \\
\text { Imbalance }\end{array}$ & 17.135 & 1.39 & 65.337 & 0.38 & -242.181 & -0.96 & 33.163 & 0.20 \\
\hline $\begin{array}{l}\text { Lag Bond Fire } \\
\text { Sales }\end{array}$ & 266.571 & 0.99 & 62.258 & 0.35 & 58.531 & 0.68 & -6.432 & -0.17 \\
\hline Lag Bond BAS & 0.132 & 0.09 & 0.679 & 1.01 & 0.288 & 0.92 & $-0.476^{* *}$ & -2.36 \\
\hline $\begin{array}{l}\text { Lag Bond } \\
\text { Modified } \\
\text { Duration }\end{array}$ & $-3.663^{* *}$ & -2.06 & -3.170 & -1.15 & -0.592 & -0.24 & -1.497 & -1.53 \\
\hline $\begin{array}{l}\text { Lag Bond } \\
\text { Realized } \\
\text { Volatility }\end{array}$ & $105.588^{* *}$ & 2.60 & 8.737 & 0.13 & -9.736 & -0.16 & $57.943^{* * *}$ & 2.83 \\
\hline $\begin{array}{l}\text { Lag Repo } \\
\text { Quantity }\end{array}$ & $-110.803^{* * * *}$ & -3.88 & $-159.985^{* * * *}$ & -3.63 & $-128.216^{* *}$ & -2.14 & 7.301 & 0.31 \\
\hline Lag Repo Trades & $3.612^{* * *}$ & 4.17 & $7.782^{* * *}$ & 6.35 & $7.845^{\text {**** }}$ & 4.23 & 0.680 & 0.82 \\
\hline $\begin{array}{l}\text { Lag Repo Net Order } \\
\text { Flow }\end{array}$ & $-92.409^{*}$ & -1.93 & 3.681 & 0.05 & $-152.101^{* *}$ & -2.22 & 16.577 & 0.66 \\
\hline Other controls: & & & & & & & & \\
\hline On-the-run & $\mathrm{Y}$ & & $\mathrm{Y}$ & & $\mathrm{Y}$ & & $\mathrm{Y}$ & \\
\hline Off-the-run & $\mathrm{Y}$ & & $\mathrm{Y}$ & & $\mathrm{Y}$ & & $\mathrm{Y}$ & \\
\hline SMP & $\mathrm{Y}$ & & $\mathrm{Y}$ & & $\mathrm{Y}$ & & $\mathrm{Y}$ & \\
\hline $\begin{array}{l}\text { Reopening } \\
\text { Auction } \\
\text { Days (R) }\end{array}$ & $\mathrm{Y}$ & & $\mathrm{Y}$ & & $\mathrm{Y}$ & & $\mathrm{Y}$ & \\
\hline $\begin{array}{l}\text { First and Second } \\
\text { Reopenings (A) }\end{array}$ & $\mathrm{Y}$ & & $\mathrm{Y}$ & & $\mathrm{Y}$ & & $\mathrm{Y}$ & \\
\hline $\begin{array}{l}\text { Type of Repo } \\
\text { Contract }\end{array}$ & $\mathrm{Y}$ & & $\mathrm{Y}$ & & $\mathrm{Y}$ & & $\mathrm{Y}$ & \\
\hline $\begin{array}{l}\text { Bond Fixed } \\
\text { Effects }\end{array}$ & $\mathrm{Y}$ & & $\mathrm{Y}$ & & Y & & Y & \\
\hline Observations & & 99,468 & & 49,587 & & 51,435 & & 45,972 \\
\hline Adjusted $R^{2}$ & & 0.582 & & 0.647 & & 0.841 & & 0.858 \\
\hline
\end{tabular}

Note. Pooled regression results over four subperiods. First period: from April 1, 2003 to August 8, 2007. Second period: from August 9, 2007 to December $31,2009$. Third period: from January 1, 2010 to February 10, 2012. Fourth period: from February 11, 2012 to December 6, 2013. Pooled regressions are estimated using robust standard errors and a between effects estimator, which only accounts for cross-sectional variability. Variables' definitions and measurements are explained in Tables 5 and 6.

${ }^{* * * *}$ Indicates $1 \%$ significance;

** $5 \%$ significance;

* $10 \%$ significance. 
each day's trading, we sort the sample bonds into these seven residual maturity buckets and estimate the model for specialness for each bond subsample. The estimation results are reported in Table 8 . We find that, on average, the model explains more of the variation in specialness for subsamples of repos with lower residual maturity of the collateral. The highest adjusted $R^{2}$ is obtained for 5-year bonds $(32.19 \%)$ and the lowest adjusted $R^{2}$ is obtained for 30-year bonds (20.08\%). All results for bond collateral supply, bond information uncertainty (Lag Bond BAS), and repo liquidity (Lag Repo Trades), remain generally invariant across all maturity portfolios. Lag Bond Realized Volatility is mainly significant for 6-month, 3-year, and 15-year residual maturity subsamples. Lag Bond Modified Duration presents the expected negative and significant coefficients only for the 3- and 7 -year residual maturity subsamples, whereas the coefficient is significant and positive for 5-year residual maturity bonds. The SMP dummy is strongly significant at the $1 \%$ level for 3-, 5-, and 7-year BTPs. This is in line with the 4.5-year average modified duration of Italian instruments purchased during the SMP, as disclosed by the ECB. The SMP dummy is also significant for BTPs with 10-, 15-, and 30-year maturities, but at lower significance levels $(5 \%, 10 \%$, and $10 \%$ significance, respectively).

\section{4 | Testing Duffie's cross-sectional predictions}

Inspired by the unexpected, consistently positive coefficient for the bond bid-ask spread on specialness, we conjecture that the result may be driven by time series effects. In contrast, Duffie's (1996) model makes cross-sectional predictions: if, at the same time, two bonds have similar characteristics but different liquidity, the most liquid bond is the more desirable and more likely to go on special. Therefore, we now focus on a cross-sectional model for specialness. We compute between effects estimates and present the results in Table 9. The coefficient for the bid-ask spread becomes negative and significant at the $5 \%$ level only in the post-crisis period. Notably, it appears insignificant during the crisis periods and pre-crisis period. This evidence seems to indicate that Duffie's (1996) prediction of a negative relationship between bond illiquidity and repo specialness does not hold at times of high uncertainty. ${ }^{32}$

\section{5 | SUMMARY AND CONCLUSIONS}

We examine several factors that determine the variation in the degree of specialness of repos with Italian government bonds as special collateral. We use a rich dataset of intraday bond and daily repo data from April 1, 2003 to December 6, 2013-a longer sample period than any previous work in the literature. We conclude that the supply of the collateral bond and the liquidity of the repo contracts have a fundamental influence on the degree of specialness of repo contracts (ON1, TN, and SN) before, during, and after the GFC and the ESDC. The order flow dynamics in the bond and repo markets unveil the effects on repo specialness of high demand pressure for collateral and high short-selling activity via reverse repos.

The collateral bonds' volatility, along with the collateral bonds' relative bid-ask spreads are the most important factors for explaining specialness. After controlling for bond supply, we find that increases in the bid-ask spreads are mostly associated with increases in specialness. Thus, the bid-ask spread seems to reflect information uncertainty and speculative demand rather than liquidity. Additionally, we study a novel variable that captures the fire sales of bonds at portfolio levels, and we find that, on average, larger negative values for this variable (i.e., a higher volume of sales) tend to be associated with lower bond specialness.

The subsample analysis reveals that the impact of some factors changes in magnitude and direction before, during, and after the GFC and the ESDC, and allows us to enhance our understanding of the determinants of the time variation of specialness. The volatility in the bond market has the highest impact on specialness during crisis periods. Large fire sales are significant only during the ESDC and are associated with lower specialness; hence, the substitute effect prevails over the high-value effect.

The bond purchases undertaken by the ECB as unconventional monetary interventions during the ESDC also have a great impact on Italian bonds' specialness.

Finally, our study suggests that a detailed control for the dynamics of bond auctions is essential to understand the time variation of specialness for different repo terms. First, we observe that the effect of auctions on specialness tends to decrease over consecutive auction reopenings (which are typical of Italian government bonds) and it also varies across bond maturities. Second, we find that specialness tends to increase steadily for all repo terms from the auction announcement date until 3, 2, and 1 day before the collateral bond auction settlement date, respectively, for SN, TN, and ON1 repos. Afterwards, specialness tends to decrease, sometimes very sharply. When a new auction is announced, Treasury primary dealers start bidding and they hedge the risk of the winner's curse (i.e., of acquiring too many of the new tranches of an existing bond) by short selling the already existing instrument. The short selling is carried out in conjunction with a reverse repo. If the winner's curse is realized, the dealers' inventories of over-purchased bonds can be reduced by covering short sales and delivering collateral on the reverse repos. Primary dealers are happy to accept lower special rates in order to get temporary ownership of the collateral and short sell it. Consequently, the repo specialness 
increases prior to the bond auction. Strikingly, we observe that the pattern of repo specialness is aligned with the collateral bond auction settlement day, allowing the dealer to off load overbought bonds via reverse repos. That is why the specialness varies according to the term of the repo contract. Specifically, the special reverse-repo has its second leg (collateral delivery and receipt of cash with interest) set on the auction settlement date, when the additional bond supply becomes available to primary dealers. So, for example, if primary dealers hedge using a TN reverse repo, they enter into the contract 2 days before the auction settlement, as the second leg of TN is set 2 days after the repo trades. At this time, there will be a sharp increase in the demand of TN reverse repos for the specific bond; its special repo rate will decrease and its specialness will rise. Although this mechanism has been suggested by previous literature when studying the dynamics of bond yields around auctions, it has never been clearly explained as we do in this paper where we examine the term structure of repos.

\section{ENDNOTES}

${ }^{1}$ In our analysis, we consider operations conducted by both the Bank of Italy and the European Central Bank (ECB).

2 These authors use changes in the special repo rates as a proxy for changes in specialness, hence assuming no changes in the GC rate. They argue that time-dummies can be used to control for the effects of changes in the GC rates, but this approach cannot be easily applied to the Italian market. The ECB money market rates act as benchmarks for all GC repos that use Treasuries issued by countries in the Eurozone as collaterals. Thus, similarly to the United States, the dynamics of the main refinancing rates in the Eurozone are affected by ECB decisions. However, the Italian GC rate also captures country-specific risks.

${ }^{3}$ Our paper largely extends an initial analysis by Dufour and Skinner (2005) that uncovered possible effects of speculative demand on Italian Treasuries only during the period from 2003 to 2005.

${ }^{4}$ Lou et al. (2013) discuss both the dealers' limited risk-bearing capacity and the imperfect capital mobility of end-investors. The dealers' limited risk-bearing capacity relates to the fact that primary dealers are risk averse or have costly capital, so they need to be compensated for the large position in the asset and the price risk they take on their inventory in the auction. This compensation comes in the form of higher auction yields from which the dealers generate trading profits (see also Fleming \& Rosenberg, 2007). If the dealers' risk aversion or the price risk is larger, one may expect them to charge a higher yield at the auction. Due to hedging pressures, other bond series, and in particular those for which the returns are highly correlated with the return on the new series, will also see an increase in the yield (see Beetsma et al. (2016) for empirical evidence on the Italian bond market). The imperfect capital mobility of end investors relates to the fact that many arbitrageurs and end investors cannot absorb the large Treasury supply coming from dealers ahead of auctions as they have insufficient resources. This also creates a downward pressure on the price of
Treasuries in the secondary market ahead of auctions, which we have also verified for our sample of bonds.

${ }^{5}$ See Appendix A for more discussion on repo markets.

${ }^{6}$ In the original MTS dataset there are several missing observations for the modified duration (e.g., BTPs with residual maturity lower than 6 months). We have computed the modified durations for all these bonds with missing information.

${ }^{7}$ The daily repo rates for GC contracts for other main European issuers, such as France and Germany, are not always available in the MTS Time Series database.

${ }^{8}$ Note that high peaks in specialness could be the results of negative special repo rates. Dealers would be willing to accept negative repo rates in order to have access to a bond that is scarce in the market, but it is required to cover their short-positions.

${ }^{9}$ The Bank of Italy and the Italian Treasury cooperate closely when managing the debt operations: see http://www.dt.tesoro.it/en/ debito_pubblico/; http://www.bancaditalia.it/.

${ }^{10}$ We do not consider 7-year bonds because there is just one instrument available in the primary market and another one traded in MTS. Moreover, 7-year bonds are not proper BTPs; they are defined as "Certificates."

${ }^{11}$ In an exchange transaction, a new Treasury bond is issued in exchange of other bonds or certificates; this second leg of the contract is a buyback ("indirect"). Only specialists in government bonds are allowed to participate in exchange transactions. There are two types of buybacks: (a) direct buybacks, where the buyback price is fixed in the morning of the day of the operation; and (b) indirect buybacks, which are carried out via exchange transactions. There is no regularity in the observed behaviour for these two types of central bank liquidity operations; they are more opaque than normal auctions. We also lack information on historical announcements and volumes for exchanges and buybacks.

12 The graphic evidence on the effect of six reopening auctions on specialness for all repo terms is unreported for space constraints, but it is available upon request. There is some useful graphic evidence in Figure 3, with regards to the first reopening auction.

${ }^{13}$ Beetsma et al. (2018) find that more successful auctions of euro area public debt, as captured by higher bid-to-cover ratios, lead to lower secondary-market yields following the auctions. Interestingly, they suggest that a forward-looking proxy of the bid-to-cover ratio would be very useful for issuers to help them set a reasonable auction size. Specialness may reflect the order flow of primary dealers' clients and thus may be used by issuers to predict the interest in the next auction.

14 The TN reverse repo contract has its first leg (collateral purchase/lending cash) 1 day after the reverse-repo trade, and its second leg (collateral re-sale/receipt of cash and interest) 2 days after the reverse repo trade.

15 The ON1 reverse repo contract has its first leg (collateral purchase/lending cash) on the day of the reverse-repo trade, and its second leg (collateral re-sale/receipt of cash and interest) 1 day after. The SN reverse repo contract has its first leg (collateral purchase/lending cash) 2 days after the reverse repo trade, and its second leg (collateral re-sale/receipt of cash and interest) 3 days after.

${ }^{16}$ In general, we think of high repo specialness as related to bonds being more desirable and attractive for speculators, so in higher 
demand (Duffie, 1996). However, the increase in specialness ahead of an auction has a different motivation. It is, in fact, caused by primary dealers' aggressive hedging activity. They sell short the already-issued bond in the cash market using reverse repos. This lowers the special rate and increases the specialness. Then the primary dealers use the newly-issued bond obtained at the reopening auction to close their reverse repo positions.

${ }^{17}$ For instance, Dunne, Hau, and Moore (2015) use inventory (trade) imbalances as a measure of relative depth of the best quotes of Italian bonds traded on MTS.

18 Bougheas and Kirman (2018) study the impact of fire sales on the interbank mark and find that the severity of shocks induced by extreme ("catastrophic") fire sales determines the formation of links in the interbank network.

19 The Bank of Italy used to release a first announcement on the identity of the instruments 5 days before the auction date, followed by the main announcement 3 days before the auction date with all details about the allocated amounts. Nowadays, all communications are given in a single announcement that takes place 3 days before the main auction.

${ }^{20}$ Unfortunately, we do not know the ISINs of the bonds purchased by the ECB because this information was not disclosed to the public.

${ }^{21} F$ tests and Hausman (1978) tests confirm the need to control for fixed effects, but not for random effects.

${ }^{22}$ Standard errors are clustered by bond and by type of repo contract due to the different average standard deviations observed for the three types of repos (see Section 2.1, Table 3). In unreported results, we use OLS with clustered standard by time (Arellano (1987)). The results with time-clustered standard errors are qualitatively consistent with those reported in Table 6.

${ }^{23}$ On September 6, 2012 the SMP was replaced by the Outright Monetary Transactions programme (OMT), which was never used by ECB in our sample period. The main purchase of Italian bonds ended in February 2012.

24 The average residual maturities of BTPs purchased by the ECB was 4.5 years, thus we could expect this dummy to be more significant for shorter residual maturities. See https://www.ecb.europa.eu/press/ pr/date/2013/html/pr130221_1.en.html

25 The specialists are intermediaries selected by the Italian Central Bank and the Italian Treasury (Ministry of Economics and Finance) among the primary dealers displayed on the MTS electronic market for government securities; they are allowed to take part in supplementary auctions, exchange transactions, and buyback operations with the specific mandate to supply liquidity. The supplementary auction is an additional non-competitive placement of bonds that is reserved to the selected specialist primary dealers. Specialists can take part in this non-competitive placement only if they have submitted at least one application at a valid price in the corresponding competitive placement (ordinary auction). Usually, supplementary auctions take place one day after the corresponding ordinary auction and settle on the same date. It is not mandatory for specialists to trade in supplementary auctions.

${ }^{26}$ It is worth mentioning that the instruments traded on the MTS are bonds that have already significant levels of liquidity in order to be admitted for trading among dealers and for pledging of collateral.

${ }^{27}$ Corradin and Maddaloni (2017) find that the effects of other ECB liquidity operations, such as the 3-year Long-term Refinancing
Operations, are insignificant for specialness. We therefore decide to use only the SMP dummy in our models.

${ }^{28}$ For more information about this methodology see Huettner and Sunder (2012).

${ }^{29}$ On August 9, 2007, BNP Paribas announced the decision to cease three major hedge- funds which that were specialized in U.S. mortgage debt. This date is considered as the start of the GFC (Afonso, Arghyrou, \& Kontonikas, 2014).

${ }^{30}$ Arghyrou and Kontonikas (2012) provide a detailed account of the events and market reactions during these two distinct phases of the ESDC.

${ }^{31}$ It is important to note that instruments with just 6 months to maturity could be subject to specific liquidity and trading dynamics when approaching the maturity date. Specifically, as they are not involved in reopening auctions, they cannot be associated with possible onthe-run/off-the-run status. Also, 7-year bonds are never on-the-run or off-the-run, and never involved in reopening auctions over our sample period.

${ }^{32}$ For brevity, we show in Appendix D that our results are robust to additional checks.

33 Two CCPs are active in the Italian sovereign repo market: Cassa di Compensazione e Garanzia (CC\&G) and LCH Clearnet SA (LCH), used respectively by Italian and foreign financial institutions. Market participants have made a larger use of the clearing services offered by CCPs in recent years due to regulatory developments as well as enduring risk aversion in financial markets (Miglietta, Picillo, \& Pietrunti, 2015). The advantages that central clearing offers to market participants relate primarily to counterparty risk reduction and to cash and collateral savings through multilateral netting. Nonetheless, participating in a CCP entails some costs, such as annual participation fees, contributions to the default fund and the payment of initial and variation margins. In centrally cleared repo transactions, CCPs require both parties to post initial margins with the $\mathrm{CCP}$ on the net amount of the collateral due, with the aim of providing the CCPs with sufficient resources to mitigate potential risks. In addition, participants may be asked to post variation margins following mark-tomarket valuation of individual positions.

${ }^{34}$ Several observations show negative specialness. We discard only four outliers out of about 250,000 observations (two observations for $\mathrm{TN}$ repos and two for $\mathrm{SN}$ repos). We keep all the other negative values as these are plausible observations. For example, a downward movement of the GC rate at the end of the day can result in negative specialness for a special repo traded more heavily earlier in the day.

${ }^{35}$ We create seven portfolios based on bonds' residual maturities equal to 3 years, 5 years, 7 years, 10 years, 15 years, 30 years, and less than or equal to 6 months. The 6-month portfolio is included to control for liquidity noise (see Darbha \& Dufour, 2013) and the potential presence of coupon-stripping operations.

${ }^{36}$ Coval and Stafford (2007) consider the $10^{\text {th }}$ percentile as the threshold for general selling pressure (fire sales). However, they construct this measure for the equity market, which is more volatile than Treasuries and more easily subject to selling pressure. We think that taking the $5^{\text {th }}$ percentile of the bond portfolios' relative trade imbalance is a more suitable choice for our case.

${ }^{37}$ We use an optimal number of three lags for the Newey-West estimator. The estimation is robust to the inclusion of a higher number of lags. 
${ }^{38}$ Note that the first issue day is not considered, since trades and proposals on the collateral bond market usually start some days after the issue day.

${ }^{39}$ All these results are not reported for brevity, but are available from the authors upon request.

\section{ORCID}

\section{Ivan Sangiorgi (D) https://orcid.org/0000-0002-8344-9983}

\section{REFERENCES}

Afonso, A., Arghyrou, M. G., \& Kontonikas, A. (2014). Pricing sovereign bond risk in the European Monetary Union area: An empirical investigation. International Journal of Finance and Economics, 19(1), 49-56. https://doi.org/10.1002/ijfe.1484

Arellano, M. (1987). Practitioners' corner: Computing robust standard errors for within-groups estimators. Oxford Bulletin of Economics and Statistics, 49, 431-434.

Arghyrou, M. G., \& Kontonikas, A. (2012). The EMU sovereign-debt crisis: Fundamentals, expectations and contagion. Journal of International Financial Markets, Institutions \& Money, 22, 658-677. https://doi.org/10.1016/j.intfin.2012.03.003

Beetsma, R., Giuliodori, M., de Jong, F., \& Widijanto, D. (2016). Price effects of sovereign debt auctions in the euro-zone: The role of the crisis. Journal of Financial Intermediation, 25, 30-53. https://doi. org/10.1016/j.jfi.2014.11.004

Beetsma, R., Giuliodori, M., Hanson, J., \& de Jong, F. (2018). Bid-tocover and yield changes around public debt auctions in the euro area. Journal of Banking and Finance, 87, 118-134. https://doi.org/ 10.1016/j.jbankfin.2017.10.006

Bougheas, S., \& Kirman, A. (2018). Systemic risk and the optimal seniority structure of banking liabilities. International Journal of Finance and Economics, 23(1), 47-54. https://doi.org/10.1002/ijfe. 1602

Buraschi, A., \& Menini, D. (2002). Liquidity risk and specialness. Journal of Financial Economics, 64(2), 243-284. https://doi.org/ 10.1016/S0304-405X(02)00077-6

Corradin, S., \& Maddaloni, A. (2017). The importance of being special: Repo markets during the crisis. ECB Working Paper.

Coval, J., \& Stafford, E. (2007). Asset fire sales (and purchases) in equity markets. Journal of Financial Economics, 86(2), 479-512. https://doi.org/10.1016/j.jfineco.2006.09.007

D'Amico, S., Fan, R., \& Kitsul, Y. (2018). The scarcity value of treasury collateral: Repo-market effects of security-specific supply and demand factors. Journal of Financial and Quantitative Analysis, 53(5), 2103-2129. https://doi.org/10.1017/S0022109018000790

Darbha, M., \& Dufour, A. (2013). Microstructure of the euro-area government bond market. In K. H. Baker, \& H. Halil Kiymaz (Eds.), Microstructure of the Euro-Area Government Bond Market. Market microstructure in emerging and developed markets: Price discovery, information flows, and transaction costs (pp. 39-58). Wiley. https://www.onlinelibrary.wiley.com/action/showCitFormats?doi= 10.1002/9781118681145.ch3

Duffie, D. (1996). Special repo rates. Journal of Finance, 51(2), 493-526. https://doi.org/10.1111/j.1540-6261.1996.tb02692.x
Dufour, A., \& Skinner, F. (2005). Degrees of specialness: An empirical analysis of the Italian BTP repo market. University of Reading ICMA Centre Working Paper.

Dufour, A., Stancu, A., \& Varotto, S. (2017). The equity-like behaviour of sovereign bonds. Journal of International Financial Markets Institutions and Money, 48, 25-46. https://doi.org/10.1016/j.intfin. 2016.11.014

Dunne, P. G., Hau, H., \& Moore, M. J. (2015). Dealer intermediation between markets. Journal of the European Economic Association, 13(5), 770-804. https://doi.org/10.1111/jeea.12118

Dunne, P. G., Moore, M., \& Portes, R. (2006). European government bond markets: Transparency, liquidity, efficiency. CEPR Research Report, Corporation of London.

Fisher, M. (2002). Special repo rates: An introduction. Economic Review - Federal Reserve Bank of Atlanta, 87(2), 27-44.

Fleming, M. J. \& Rosenberg, J. V. (2007). How do treasury dealers manage their positions? Federal Reserve Bank of new York, Staff Reports No. 299.

Graveline, J. J., \& McBrady, M. R. (2011). Who makes on-the-run treasuries special? Journal of Financial Intermediation, 20, 620-632.

Hausman, J. A. (1978). Specification tests in econometrics. Econometrica, 46(6), 1251-1272. https://doi.org/10.2307/1913827

Huettner, F., \& Sunder, M. (2012). Axiomatic arguments for decomposing goodness of fit according to Shapley and Owen values. Electronic Journal of Statistics, 6, 1239-1250. https://doi. org/10.1214/12-EJS710

Jordan, B. D., \& Jordan, S. D. (1997). Special repo rates: An empirical analysis. Journal of Finance, 52(5), 2051-2072. https://doi.org/10. 1111/j.1540-6261.1997.tb02750.x

Keane, F. (1995). Expected repo specialness costs and the treasury auction cycle. Federal Reserve Bank of New York Working Paper No. 9504.

Krishnamurthy, A. (2002). The bond/old-bond spread. Journal of Financial Economics, 66(2), 463-506. https://doi.org/10.1016/ S0304-405X(02)00207-6

Lou, D., Yan, H., \& Zhang, J. (2013). Anticipated and repeated shocks in liquid markets. Review of Financial Studies, 26(8), 1891-1912. https://doi.org/10.1093/rfs/hht034

Miglietta, A., Picillo, C., \& Pietrunti, M. (2015). The impact of CCPs' margin policies on repo markets. BIS Working Papers No. 515, Monetary and Economic Department.

Moulton, P. C. (2004). Relative repo specialness in U.S. treasuries. The Journal of Fixed Income, 14, 40-47. https://doi.org/10.3905/jfi. 2004.419572

Newey, W. K., \& West, K. D. (1987). A simple, positive semi-definite, heteroskedasticity and autocorrelation consistent covariance matrix. Econometrica, 55, 703-708. https://doi.org/10.2307/1913610

Sundaresan, S. (1994). An empirical analysis of U.S. treasury auctions. The Journal of Fixed Income, 4(2), 35-50. https://doi.org/10.3905/ jfi.1994.408109

How to cite this article: Dufour A, Marra M, Sangiorgi I, Skinner FS. Explaining repo specialness. Int J Fin Econ. 2020;25:172-196. https://doi.org/10. 1002/ijfe.1746 


\section{APPENDIX A.: 5.1 | The repo market}

A repurchase agreement (repo) is a collateralized loan based on a simultaneous sale and forward agreement to repurchase a security at a future maturity date for its original value plus an interest rate, the repo rate, for the use of the cash. The repo buyer borrows cash after pledging a security as collateral. The repo seller lends cash and collects the repo (interest) rate. In case the repo buyer fails to repurchase the collateral, the counterparty (repo seller) can dispose of the collateral and use it to compensate their losses. Repo transactions are typically used for financing purposes via general collateral (GC) repos or to obtain specific securities via special repos. GC repos are mainly cash-driven as the collateral can be any security from a predefined basket of securities, whereas special repos are security-driven as the collateral is restricted to a single security.

Because a repo is a safer way to lend cash, lenders are generally willing to lend more and at better conditions than in an unsecured lending agreement. In addition, institutions lending through repos are generally required by the regulator to hold less regulatory risk capital than in the case of unsecured lending. Consequently, over the last 10 years, there has been a gradual shift of liquidity from deposit markets to repos. However, the safety of a repo contract ultimately relies on the adequacy of its collateral. Repo traders prefer liquid collaterals and accept illiquid collaterals only subject to appropriate initial margins and haircuts. The repo collateral is continuously revaluated and, if its value falls, the repo seller can require extra collateral (this process is called margin maintenance). Moreover, the repo seller (i.e., the lender) needs to be sure that, in the event of a default of the counterparty, the seller can: (a) sell the collateral easily and without interference from the other creditors of the defaulter; and (b) reduce their exposure to the defaulter by "netting" debts owed by the defaulter against debts owed to the defaulter. Because of the burden of all these operational requirements, some repo traders outsource the management of their collateral to agents; this system is called tri-party repo and it is the most common arrangement in the U.S. repo market. Margin requirements and maintenance, collateral valuation, and counterparty risk management can be also delegated to a central clearing counterparty (CCP). This system is more common in the European repo markets. ${ }^{33}$ Central banks set benchmark interest rates. Repo rates are affected by changes in these benchmark rates but ultimately they are determined by private institutions that trade on secondary markets (such as the MTS). Most central banks (including the ECB) use repos as tools for open market operations to control short-term interest rates.

Generally, repos are classified as "buy/sell-back" or "classic" repos. A buy/sell-back repo is often undocumented and structured as two separate legal transactions, whereas a classic repo includes both legs together in one legal transaction. Buy/sell-back and classic repos are precisely the same in terms of their economic function and in Europe they both transfer the legal title of the bond to the counterparty-lender via an outright sale. However, a classic repo offers greater protection against counterparty credit risk for the lender. For instance, the lender can demand additional collateral if the interest rate spikes and the value of existing collateral falls below the outstanding loan amount. This is not possible with buy/sell-back repos. All repo transactions we study are buy/sell-back repos, as these are the only repo contracts used in Italy.

\section{APPENDIX B.: 5.1 | Filtering steps of tick-by-tick bond data}

The following steps are used to filter the intraday bond data:

- We consider only quotes recorded during the regular daily trading hours from 8:15 a.m. until 5:00 p.m. CET and discard the last $30 \mathrm{~min}$ of the trading day ending at 5:30 p.m.

- Many of our sample bonds trade on a local market (the MTS), and on a European market (the Euro MTS). Market makers can submit a quote revision simultaneously to both markets, but the quote update may reach the two trading systems at slightly different times. In order to account for these latency issues, we assign the same time stamp to quotes submitted to these parallel platformsMTS and Euro MTS - when they have the same price and are recorded either at the same time or with a small time delay of up to 3 milliseconds.

- We construct the consolidated order book using both MTS and Euro MTS quotes and compute the overall best bid and ask prices.

- We discard consolidated quotes with negative bid-ask spreads. These may appear when the best quotes on the two alternative platforms diverge temporarily.

- We discard excessive misalignments between special and GC repo rates (only four outliers are detected with specialness lower than $-100 \mathrm{bps}) .^{34}$

- We discard quotes with extremely high bid-ask spreads, since trade execution is unlikely to take place when bidask spreads are so large.

On the MTS, dealers with market-making obligations cannot remove their quotes, but they are allowed to temporarily increase the spread to signal that they are not active. Short periods of unreasonably high bid-ask spreads are often the result of dealers significantly increasing their ask quotes and/or reducing their bid quotes. No trades are executed at these extreme quote levels. Therefore, we determine a maximum tradable spread level by considering the distribution of 
the relative bid-ask spreads observed in the consolidated order books right before trade executions. We conduct this analysis over seven residual maturity buckets for every year of the sample. We discard proposals with relative bid-ask spreads greater than the $99^{\text {th }}$ percentile of the distributions, for every maturity-bucket and every year. As expected, we observe that on average, longer-maturity bonds are traded at higher relative bid-ask spreads than shorter-maturity bonds.

\section{APPENDIX C.: 5.1 | Construction of the fire sales variable}

To obtain a fire sale measure, we first construct daily rebalanced bond portfolios on the basis of their residual maturity. ${ }^{35}$ The reason we construct portfolios on the basis of the bonds' residual maturity is that we expect that lowermaturity BTPs are preferred to longer-maturity ones during fire sales due to their relatively higher liquidity that reduces the negative price impact of the fire sales. Second, we compute for each portfolio the trade imbalance as the difference between the daily aggregate buyer-initiated volume minus the daily aggregate seller-initiated volume from all repoed bonds included in the portfolio. Then, we divide the portfolio trade imbalance by the monthly average of the total daily exchanged volumes for all bonds in the same portfolio. This variable represents a "relative" portfolio trade imbalance. The reason we standardize the trade imbalance measure by the monthly average of the total exchanged volume of bonds in the portfolio is to "distinguish" a fire-sale accompanied by an extreme selling pressure from a general scarcity of similar and highly substitutable instruments in the secondary market. Third, we look at the distribution of each portfolio's relative trade imbalance for different repo terms and select as threshold value the $5^{\text {th }}$ percentile of the distribution, which detects high selling pressure. Fourth, we compute daily returns for each bond using the mid-price observed at the last quote's update before 5:00 p.m. in the consolidated bond order book. Fifth, we compute the equally-weighted portfolio returns and look at the distribution of each portfolio's mean return for each repo term. We select the $5^{\text {th }}$ percentile of the distribution, which detects extreme price drops. Finally, we discard from the $5^{\text {th }}$ percentile of the distribution of the "relative" portfolio trade imbalance the observations that do not belong also to the $5^{\text {th }}$ percentile of the distribution of the equally-weighted portfolio returns. The rationale of this last condition is to select as proxy for fire sales only the extreme aggressive selling pressure, which is also reflected in extreme negative returns. Table A1, Panels A and B show the fire-sales thresholds for different repo terms and bond maturities. ${ }^{36}$

\section{APPENDIX D.: 5.1 | Robustness checks}

We perform several robustness checks on our main results. First, we re-estimate our model with heteroscedasticity and serial correlation robust standard errors that are computed using the Newey-West methodology (Newey \& West, 1987). ${ }^{37}$ We observe no changes in the significance of the explanatory variables, except for the off-the-run dummy, which is now significant at the $1 \%$ significance level.

Second, in order to understand the stability of the estimated coefficients and their interaction with other explanatory variables, we estimate a parsimonious univariate model for each explanatory variable and then gradually add the larger set of remaining explanatory variables. The only puzzling result from this check comes when controlling for the effect of fire sales in a univariate model. Initially, we find a negative and significant impact on specialness that is consistent with the "high-value sale effect." That is, the bond on special is a desirable instrument and is preferred for speculative trades, so it is the first to go on fire sale among a group of similar bonds. However, when we also control for the

TABLE A 1 Bond fire sales

\begin{tabular}{|c|c|c|c|c|c|c|c|}
\hline \multicolumn{4}{|c|}{$\begin{array}{l}\text { Panel A: } \\
\text { Relative portfolio Trade Imbalance, } 5^{\text {th }} \text { Percentile }\end{array}$} & \multicolumn{4}{|c|}{$\begin{array}{l}\text { Panel B: } \\
\text { Portfolio Returns, } 5^{\text {th }} \text { Percentile }\end{array}$} \\
\hline Residual Maturity & ON1 & $\mathbf{T N}$ & $\mathbf{S N}$ & Residual Maturity & ON1 & $\mathbf{T N}$ & $\mathbf{S N}$ \\
\hline 6 months & -1.3191 & -1.4765 & -1.2737 & 6 months & -0.0004 & -0.0004 & -0.0004 \\
\hline 3 years & -0.8990 & -0.5188 & -0.4786 & 3 years & -0.0023 & -0.0020 & -0.0021 \\
\hline 5 years & -1.0331 & -0.7881 & -0.6755 & 5 years & -0.0050 & -0.0047 & -0.0049 \\
\hline 7 years & -1.4515 & -1.0941 & -0.9640 & 7 years & -0.0055 & -0.0060 & -0.0062 \\
\hline 10 years & -0.8178 & -0.6752 & -0.6536 & 10 years & -0.0071 & -0.0072 & -0.0074 \\
\hline 15 years & -1.4531 & -0.9820 & -0.9305 & 15 years & -0.0081 & -0.0080 & -0.0082 \\
\hline 30 years & -1.4272 & -1.1172 & -0.9831 & 30 years & -0.0092 & -0.0095 & -0.0099 \\
\hline
\end{tabular}

Note. Panel A reports the $5^{\text {th }}$ percentile values of relative trade imbalance for each residual-maturity bond portfolio. Panel B reports the $5^{\text {th }}$ percentiles of the portfolio-returns for each residual-maturity bond portfolio. The reported values correspond to the selected thresholds for the construction of the Bond Fire Sales variable. Portfolios are rebalanced every day. 
bond bid-ask spread as additional explanatory variable, the sign of the fire-sale impact changes to positive, supporting the substitute effect (that is, special bonds can be used to obtain cash at lower rates, so they are the last to go on fire sale among a group of similar bonds). Fire sales are negatively correlated with the bid-ask spread $(-11 \%)$ and with specialness $(-2 \%)$. Namely, large fire sales (negative net order flows triggering highly negative returns) are associated with wide bid-ask spreads and large specialness. However, once we control for illiquidity then the bonds selected for the fire sales tend to be those with relatively lower specialness.

Third, we perform a battery of additional robustness checks. We run regressions that include day-dummies for the first six auction reopenings' cycles, instead of only the first two auction reopenings. ${ }^{38}$ We observe that the effects of the auctions' cycles are insignificant after the third reopening and the effect of the third reopening is so small that it does not change the quality of the results. Also, we run regressions that include additional day dummies for 5 and 4 days before the auction dates. We observe that the effects of the auctions' cycles are insignificant before the announcement date $\mathrm{Rm} 3$, which is 3 days before the auction date.

Furthermore, we use an alternative Lag Bond Fire Sales variable computed for each single bond, rather than for maturity portfolios, but we find that this variable is insignificant. Because our previous analysis suggests that the bond fire sale effect is stronger during the ESDC sub-period (see Table 7), we also re-estimate the model for bond sub- samples of different residual maturities over the ESDC period. We find that the importance of the fire sale proxy is mainly driven by the fire sale of 30-year, 15-year and 3-year bond portfolios respectively. Then, we conduct an analysis of the effects of fire sales using the $1^{\text {st }}$ and the $10^{\text {th }}$ percentile instead of the $5^{\text {th }}$ percentile threshold. The fire sale variables computed using the $1^{\text {st }}$ and the $10^{\text {th }}$ percentile are significant when used as contemporaneous variables, but insignificant when lagged. In both specifications, their estimated coefficients are positive, thereby confirming the substitute effect (see also Table 6).

Next, we use an alternative measure of bond volatility: the 10-year interest rate cap implied volatility available in Datastream, instead of the Bond Realized Volatility. This measure of volatility changes over time but not across bonds. The lag implied volatility is significant, but with a counterintuitive negative sign. When we exclude both Lag Bond BAS (highly correlated with the implied volatility) and the SMP dummy from the model, the estimated coefficient of lag implied volatility becomes significantly positive. As seen in Table 6, the Lag Bond Realized Volatility is instead significant even after controlling for Lag Bond BAS, with the expected positive sign.

Finally, we analyse the effect on specialness of the average bid-to-cover ratio for each auction, but we do not observe any regular pattern associated with variations in specialness. ${ }^{39}$ 